\title{
Patrones culinarios asociados al camote (Ipomoea batatas) y la yuca (Manihot esculenta) entre los mayas yucatecos, ch'oles y huastecos
}

\section{Culinary Patterns Associated with the Sweet Potato (Ipomoea batatas) and the Cassava (Manihot Esculenta) among Yucatec Maya, Ch'ol, and Huastec}

\author{
LuCERo Meléndez Guadarrama ${ }^{1}$ \\ Instituto de Investigaciones Antropológicas, \\ Universidad Nacional Autónoma de México \\ JAVIER HiROSE LÓPEZ \\ Universidad de Oriente, Valladolid, Yucatán
}

\begin{abstract}
RESUMEN: El objetivo central de este trabajo consiste en describir los patrones culinarios asociados a los tubérculos de Ipomoea batatas (camote) y Manihot esculenta (yuca) entre los huastecos, ch'oles y mayas yucatecos (todos miembros de la familia linguí́stica maya), así como sus posibles usos medicinales e implicaciones rituales. Analizaremos la importancia cultural que se desprende de su uso en la cocina maya desde la época prehispánica hasta nuestros días, pues son alimentos complementarios de la dieta cotidiana que fungen también como cultivos de reserva en épocas de sequía. El análisis comparativo muestra continuidades en las formas de consumo compartidas por los tres grupos a lo largo de los siglos, asimismo se observan singularidades linguíísticas y tendencias en sus preferencias de consumo dentro de la cocina que los particularizan frente a los otros, y que a su vez definen patrones culinarios únicos. Abordaremos una perspectiva multidisciplinaria que conjunta miradas complementarias de la lingüística, la antropología de la alimentación ${ }^{2}$ y la etnobotánica, que en conjunto nos ayudan a entender la relevancia cultural de estos cultivos entre los mayas.
\end{abstract}

Palabras clave: linguiística maya, dieta, patrones culinarios, camote (Ipomoea batatas), yuca (Manihot esculenta).

\footnotetext{
${ }^{1}$ Los autores desean agradecer a los consultantes huastecos, mayas y ch'oles que participaron en nuestras entrevistas así como a los estudiantes de la licenciatura en Linguística y Cultura maya de la Universidad de Oriente, Yucatán. También agradecemos a los dos dictaminadores anónimos que hicieron sugerencias y comentarios que ayudaron a enriquecer este trabajo.

${ }^{2}$ La antropología de la alimentación es entendida en términos de Gracia-Arnaiz (2010: 365-366) como "la disciplina dedicada al estudio de las prácticas y representaciones alimentarias de los grupos humanos desde una perspectiva comparativa y holística. La antropología de la alimentación pone su atención sobre todo en los factores ecológicos, socioculturales, económicos o filosóficos que influyen en la elección de los alimentos, teniendo en cuenta, sin embargo, que existen otros de carácter biológico y psicológico".
} 
ABSTRACT: The objective of this paper is describing the culinary patterns associated to the tubers Ipomoea batatas (sweet potato) and Manihot esculenta (cassava) among the Huastec, Ch'oles and Yucatec Maya (all members of the Mayan linguistic family), as well as their medical uses and ritual implications. We will analyze the cultural importance that comes from its use in Mayan cuisine from pre-Hispanic times to the present day, since they function as complementary food of the daily diet but also work as reserve crops in times of drought. The comparative analysis exhibit continuities among the three groups compared related with the way they consume these tubers, but they also present linguistic peculiarities and cuisine tendencies individually developed. We follow a multidisciplinary perspective that combines linguistics, anthropology of food and ethnobotany, since all contribute to understand the cultural relevance of these crops among the Maya.

KeYwords: Mayan linguistics, diet, culinary patterns, sweet potato (Ipomoea batatas), cassava (Manihot esculenta).

RECEPCIÓN: 25 de octubre de 2017.

ACEPTACIÓN: 6 de febrero de 2018

DOI: $10.19130 /$ iifl.ecm.2018.52.941.

\section{Introducción}

El estudio de los tubérculos ha atraído la atención de distintos investigadores desde múltiples perspectivas tanto por su valor nutrimental como por su valor cultural entre diversos grupos indígenas del centro y sur de México (Bronson, 1966; García Quintanilla, 2000; Poot-Matu et al., 2002; Linares et al., 2008; Isendahl, 2011; Sheets et al., 2011; Ezra, Acosta y García, 2015; Lasso y Trabanino, 2015; Trabanino y Meléndez, 2017, por citar algunos de ellos). Su presencia dentro de la cocina en México es una herencia directa de los pueblos mesoamericanos, quienes desde épocas prehispánicas tempranas cultivaban y consumían diversos tipos de tubérculos para complementar su dieta. Su consumo también tiene relevancia en el ámbito económico en tanto que ha sido documentado (en época reciente y colonial) como un alimento de emergencia o de reserva durante temporadas de fuertes sequías, o bien cuando escaseaban otros suministros básicos como el maíz (Landa, 1994 [1566]: 208-9; Bronson, 1966; García Quintanilla, 2000). ${ }^{3}$

${ }^{3}$ García (2000: 272) recolectó testimonios entre mayas yucatecos de edad avanzada quienes refirieron que, durante su niñez y en época de plagas de langosta, se hacían tortillas con tubérculos, ya sea con is, 'camote' (Ipomoea batatas), o con makal (Xanthosoma yucatanense): "Cuando yo era niño de seis años había escasez de maíz por las langostas. A cada niño le dieron dos tortillas [hechas con camote molido y mezclado con la masa del maíz]. Las personas entonces iban a las milpas abandonadas en busca de camote". 
La importancia del estudio de los alimentos como marcadores culturales e identitarios entre los mayas ha sido un campo fértil de estudio en los últimos tiempos y ha derivado en una multiplicidad de trabajos que han abordado el fenómeno desde distintas perspectivas (Guevara, Pichardo y Martínez, 2017; Fernández y Matos, 2014; Herrera y Götz, 2014, entre otros). Los "patrones culinarios" entendidos como procesos complejos que comprenden la selección, preparación e ingesta de los alimentos en un determinado grupo cultural (Herrera y Götz, 2014: 69) nos permiten entender continuidades culturales entre ellos mismos y respecto a otros grupos, lo que forma parte de la identidad. ${ }^{4}$ La cocina forma parte de dichos patrones pues es

el resultado de las diferentes formas en las que los materiales son seleccionados, preparados, distribuidos, servidos y consumidos. Son en gran medida estas últimas elecciones las que constituyen distintivos culturales, ya que definen las combinaciones de los alimentos y las maneras de prepararlos, los estilos de cocina, los roles sociales del cuándo, dónde y por quiénes son preparados y comidos, así como las circunstancias bajo las cuales son consumidos (Herrera y Götz, 2014: 73).

Considerando que los tubérculos constituyen un ingrediente importante en la cocina de distintos grupos mayas tanto en el eje sincrónico actual como en el diacrónico, en este trabajo buscamos mostrar un panorama general sobre las prácticas de consumo en dicho ámbito, pues si bien los yucatecos, huastecos y ch'oles muestran algunas preferencias culinarias compartidas, también documentamos algunas otras que los particularizan. ${ }^{5}$

Este trabajo se estructura de la siguiente manera:

1) En primer lugar, abordaremos de forma general algunos aspectos etnobotánicos ${ }^{6}$ de Ipomoea batatas y Manihot esculenta.

2) Después, y con base en los principios de la paleobiolinguística, argumentaremos que los nombres mayas atestiguados para los tubérculos de sendas

${ }^{4}$ La alimentación como un elemento importante en la identidad ha sido abordado por Allen y Sachs (2012); Ayora (2012) y Pilcher (1996), entre otros.

${ }^{5}$ Los tubérculos de Ipomoea batatas y Manihot esculenta forman parte de la dieta de otros grupos mesoamericanos además de los mayas; sin embargo, el estudio comparativo de los patrones culinarios entre nuestro grupo de estudio y los otros grupos mesoamericanos rebasa el alcance del presente trabajo. Con el afán de abrir la discusión, y sin intención de agotarla, nos limitaremos a mencionar algunos aspectos relevantes compartidos con los Ikoots.

${ }^{6}$ La etnobotánica fue definida inicialmente por Harshberger (1896: 146) como "the study of the utilitarian relationship between human beings and vegetation in their enviroment, including medicinal uses". En un trabajo más reciente y con un enfoque más amplio, Casas, Blancas y Lira (2016: 1) la definen como "a research aimed at understanding what people know about plants, how plants form part of their systems of beliefs and conceptions of the world, and how humans make use and manage plants for reproducing their social and cultural life". Nos interesa pues, con este estudio, describir el conocimiento que los grupos mayas estudiados tienen sobre el cultivo y manejo de los tubérculos en cuestión y su relación con aspectos culturales propios a cada uno de ellos, que se manifiestan en su consumo alimenticio y medicinal. Dicho manejo y consumo no pasó desapercibido para los españoles durante el siglo xvi, pues hay continuas menciones sobre ello en diversos textos coloniales. 
plantas son útiles para entender la relevancia cultural que estos tienen entre los grupos mayas estudiados.

3) Posteriormente, describiremos los patrones culinarios que documentamos sobre los tubérculos del camote y la yuca; ${ }^{7}$ nos centraremos en entender su valor cultural actual, colonial y prehispánico derivado de las formas de preparación y contextos de uso, permitiéndonos apreciar algunas tendencias en las preferencias alimentarias con tubérculos entre los tres grupos mayas estudiados.

4) Por último, describiremos los usos medicinales documentados.

\section{Metodología y preguntas de investigación}

Este trabajo está guiado por las siguientes preguntas de investigación: ¿qué nos dicen los nombres en lenguas mayas sobre la historia de Ipomoea batatas y Manihot esculenta? ¿Qué tipo de prácticas culinarias están atestiguadas en los textos epigráficos y coloniales? ¿Cuáles de estas prácticas han prevalecido hasta nuestros días? ¿Dichas prácticas culinarias son comunes a los distintos grupos mayas estudiados? ¿Cuál es el papel que estos tubérculos ocupan en la dieta de los mayas actuales y pasados? Además del uso culinario, ¿qué usos medicinales se conoce que tienen o tenían los tubérculos (y en su caso, otras partes de la planta) de Ipomoea batatas y Manihot esculenta?

Para la recolección de datos se realizó trabajo etnográfico y linguiístico en seis comunidades de la región oriental del estado de Yucatán y una del vecino estado de Quintana Roo donde se entrevistó tanto a milperos como amas de casa de diversas edades. Las entrevistas se realizaron en lengua maya con la colaboración de estudiantes de la Universidad de Oriente, que son mayahablantes originarios de las localidades estudiadas. Las comunidades donde se recolectaron los datos fueron Ekpedz, San Silverio, Xuilub, Kanxoc, Popolá y Valladolid, en el estado de Yucatán y en la comunidad de Ignacio Zaragoza $(\mathrm{km} \mathrm{80),} \mathrm{municipio} \mathrm{de} \mathrm{Lázaro} \mathrm{Cárdenas,}$ Quintana Roo.

Los datos de huasteco (te:nek) fueron recolectados en nueve comunidades de habla distribuidas en los estados de San Luis Potosí y Veracruz (San Nicolás, Tanlajás; Mantetzulel, Aquismón; Tancanhuitz; San Antonio Huitzquilico, Xilitla; Francisco Villa, San Vicente Tancuayalab; Tancoco; San Francisco, Chontla; Chinampa de Gorostiza). Los datos referentes a los choles fueron retomados del trabajo de Trabanino y Meléndez (2017) y de Lasso y Trabanino (2015), así como en entrevista directa a dos hablantes; todos nuestros datos de ch'ol provienen

7 El término 'camote' puede referir a la planta Ipomoea batatas en general, o bien, solo a su tubérculo; así que hemos de aclarar que cuando en este trabajo nos referimos a 'camote' y 'yuca', nos referimos concretamente al tubérculo de las plantas (Ipomoea batatas) y de (Manihot esculenta) respectivamente, y no a otras partes de la planta como son las hojas y el tallo. El término "camote" es una palabra de origen nahua cuya forma original es kamohtli (Karen Dakin apud Linares et al., 2008: 15). 
de la región aledaña a Palenque, Chiapas. Los datos de la región donde habitan los chontales, en Tabasco, fueron retomados del trabajo de Poot-Matu et al. (2002). También fueron consultadas diversas fuentes lexicográficas con el fin de contrastar nuestros datos de campo con los registros de otros autores (Acuña, 1993; Arzápalo, 1995; Aulie y Aulie, 1996; Barrera Vásquez, 1980; Becerra y Berlin, 2008; Beltrán de Santa Rosa, 1746; Bolles, 2001; Bricker, Po’ot y Dzul, 1998; Ciudad Real, 1929; Kaufman y Justeson, 2003; Keller y Luciano, 1997; Pérez, 1898; Solís, 1949; Swadesh, Álvarez y Bastarrachea, 1970).

Dado que se trata de especies ampliamente conocidas no se colectaron especímenes botánicos, sino que únicamente se registraron sus nombres y sus usos, tanto alimenticios como medicinales. Las entrevistas fueron traducidas por los propios entrevistadores y la información sistematizada por los autores.

\section{Caracterización etnobotánica del camote (Ipomoea batatas) y la yuca (Manihot esculenta) y referencias coloniales a su cultivo y consumo}

De acuerdo con Terán, Rasmussen y May (1998), las especies americanas precolombinas que se cultivaron en la región de Yucatán son cuatro: el makal (Xanthosoma yucatanense), el camote (Ipomoea batatas), la yuca (Manihot esculenta) y la jícama (Pachirrhizus erosus). Aunque en la actualidad hay más especies —como notaron Terán et al. (ibid.) y Linares et al. (2008)—, nosotros solo nos enfocaremos en dos de ellas por ser las de uso más difundido entre los grupos mayas estudiados y sobre los cuales podemos hacer correlaciones que se remontan hasta la época prehispánica.

Entre las referencias halladas en los registros coloniales de la Nueva España respecto a las plantas de los tubérculos encontramos la de Francisco Hernández (apud Linares et al., 2008: 13), quien destacaba que

... existían algunas variedades distintas solo por el color de la raíz (pues todas tienen tallos volubles, hojas angulosas y redondas y flores con figuras de cálices blancos con púrpura).

Sahagún, en su tratado Historia General de las Cosas de la Nueva España, destinó un apartado para describir generalidades sobre el cultivo y consumo de tubérculos entre los nahuas, donde señala que

Ay otras rayzes buenas de comer, que se hazen como nabos debaxo de la tierra: alas quales llaman camotli: estas son vatatas desta tierra: comense cozidas crudas y assadas (Folio 17).

En el área maya, en la Relación de las cosas de Yucatán, Diego de Landa (1994: 208) también se ocupó de mencionar algunas características generales sobre el 
cultivo, la forma y sabor de los tubérculos, describiendo con especial interés las variedades halladas así como algunas formas de consumo:

tiene una fruta a maravilla fresca y sabrosa que se siembra y la fruta es la raíz que nace como nabo gordo y redondo cómense crudas con sal; la otra raíz que nace debajo de tierra sembrándola, que es grande mantenimiento, y es de muchas diferencias, que hay moradas, amarillas y blancas, cómense cocidas y asadas y son buena comida, y tiran algo a castañas, y ayudan, asadas, a beber.

Algunos años más tarde, en las Relaciones histórico-geográficas de la Gobernación de Yucatán se mencionan algunos aspectos relacionados con las características morfológicas y el sabor de los tubérculos:

también hay batatas que los indios llaman ys [is], pero a causa de la sequedad de la tierra son pequeñas. Asimismo, hay otra suerte de fruta que se cría debajo de la tierra, que los indios llaman chicam [chiikam], y los españoles jícamas [xicama], que son como cebollas, pero tienen el sabor como cimera de cardo... (De la Garza et al., 1983: 77).

Por su parte, en la nomenclatura etnobotánica de Barrera Marín, Barrera Vázquez y López (1976) existe la entrada léxica [Ui: raíz carnosa, bulbo o tubérculo, indistintamente], término genérico que refiere a los tubérculos entre los mayas yucatecos, pero que no es usado indistintamente para cada uno de ellos, pues como veremos se prefiere el nombre específico que existe para cada uno.

En cuanto a su clasificación botánica, Linares et al. (2008: 11) señalaron que

el género Ipomoea de la familia Convolvulaceae tiene alrededor de 600 especies distribuidas en los trópicos y subtrópicos de todo el mundo. El camote (Ipomoea batatas) es una de las ocho especies de la sección Batatas nativa que abarca desde México hasta el centro de Sudamérica.

La familia contiene 20 especies silvestres, distribuidas por la península de Yucatán (Colunga y May, 1992), mientras que la especie batatas — de acuerdo con la bibliografía - presenta entre 10 (op.cit.) y 14 variantes reportadas (Terán, Rasmussen y May-Cahuich, 1998) (Figura 1).

Por su parte, la yuca (Manihot esculenta), especie ampliamente conocida y utilizada en toda el área maya peninsular con fines principalmente alimenticios, pertenece a la familia Euphorbiaceae, y en ambiente silvestre se conocen tres especies (Colunga y May, 1992). En el poblado de Xocén, ubicado en la misma región donde se encuentran las comunidades estudiadas en el presente trabajo, se han reportado tres variedades, dos de las cuales, a su vez, presentan dos variantes. En este estudio no se lograron detectar variedades específicas, así que la información obtenida refiere al genérico "yuca", sin tomar en cuenta las variantes que pudiese haber (Figura 2). 


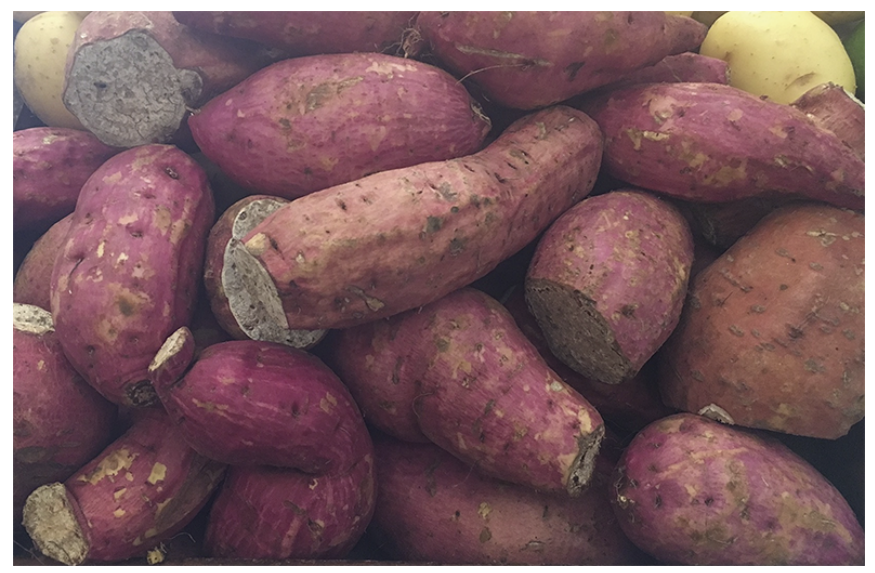

Figura 1. Ipomoea batatas (tubérculo) en el mercado de Valladolid, Yucatán. Fotografía: Lucero Meléndez.

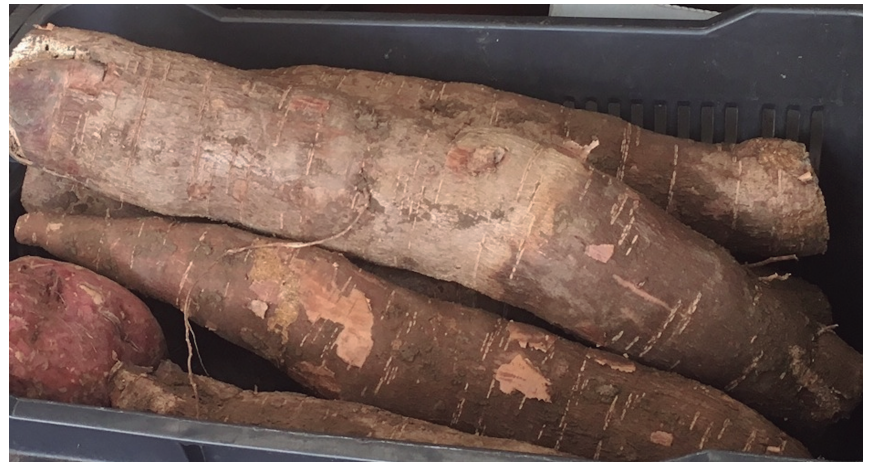

Figura 2. Manihot esculenta (tubérculo), mercado de Valladolid, Yucatán. Fotografía: Lucero Meléndez.

Lamentablemente, y en contraste con la continua mención del camote (Ipomoea batatas) como $<i z>$ en los textos coloniales yucatecos de tipo descriptivo, no se han encontrado referencias específicas a Manihot esculenta, por lo que no es posible obtener una descripción detallada de la yuca en ninguno de sus aspectos durante el periodo colonial. ${ }^{8}$ Este hecho es significativo en términos de relevancia cultural, pues mientras que el tubérculo de Ipomoea batatas no pasó desapercibido para los frailes y los relatores de los principales cultivos locales, el tubérculo de Manihot esculenta no tuvo la misma presencia en estos textos, lo que a su vez refleja una mayor preponderancia de uso del camote frente a la yuca dentro de la cocina maya (al menos entre los yucatecos coloniales).

${ }^{8}$ El nombre maya para la yuca sí está mencionado en muchos de los diccionarios coloniales, lo que no hemos encontrado es una descripción detallada en torno a sus usos en la medicina, o que refieran a formas de cultivo y consumo. 


\section{Los nombres para los tubérculos de Ipomoea batatas y Manihot esculenta entre huastecos, mayas yucatecos y ch'oles}

De acuerdo con Brown et al. (2013: 140), la reconstrucción en las protolenguas de los términos de los nombres de las plantas es posible cuando hay cognados de éstas en las lenguas hijas, mientras que las implicaciones históricas de su reconstrucción son altamente relevantes en el estudio de la paleoetnobotánica, pues "plant names that reconstruct for proto-languages tend strongly to designate plants that were substantial cultural significance for speakers of those languages" (ibid.). De esta manera, el estudio linguíístico de los términos usados para designar las plantas en conjunto con la información etnobotánica y, en su caso, arqueológica, es una tarea que puede ayudar en la reconstrucción parcial de la historia remota o reciente de un área cultural o de un grupo linguístico determinado. En la Tabla 1 se muestran los términos atestiguados para los dos tubérculos que estamos estudiando, así como las reconstrucciones propuestas para el protomaya en cada caso.

\begin{tabular}{|c|c|c|}
\hline & Ipomoea batatas & Manihot esculenta \\
\hline $\begin{array}{l}\text { nombre común } \\
\text { en español }\end{array}$ & camote /papa dulce & yuca / mandioca \\
\hline protomaya $^{9}$ & *?iis & *éiin o * eihn \\
\hline yucateco & íis/ š Pak'lis ${ }^{10} /[\mathrm{iz}]^{11}$ & ф'iim ${ }^{12} \sim$ ф'iin [Dziim] [dziin] ${ }^{13}$ \\
\hline huasteco & $i \theta^{14}$ & $\begin{array}{l}\text { pHuas }^{15}{ }^{*} \phi^{\prime} i h n \text { tyee? > t'inče? (huas SLP); } \\
\text { čiPin (HuasChip) }\end{array}$ \\
\hline chol & $\begin{array}{l}\text { Pajkum }^{16} \text { ajcum; }^{17} \\
\text { akum, ajkum }^{20}\end{array}$ & $\begin{array}{l}\text { pChol }^{18}{ }^{* * *} \phi^{\prime} i h n>\phi^{\prime}{ }^{\prime} i j n \text { ts'ijn; }{ }^{19} \\
\text { tsin / ts'i }{ }^{21}\end{array}$ \\
\hline chontal & Pakum acum 22 & cin $\mathrm{tz}^{\prime} \mathrm{in}^{23}$ \\
\hline
\end{tabular}

Tabla 1. Nombres para los tubérculos del camote ${ }^{24}$ y de la yuca en huasteco, ch'ol, chontal y yucateco.

\footnotetext{
${ }^{9}$ Las formas reconstruidas del protomaya han sido retomadas del trabajo de Kaufman y Justeson (2003: 1134; 1089). No entraremos en detalles sobre la variación que se presenta en los núcleos vocálicos de los términos reconstruidos, pues la discusión escapa a los objetivos de este trabajo. Lo que nos interesa enfatizar es la transparencia en las formas resultantes que permiten una reconstrucción incuestionable de las mismas en protomaya.

${ }^{10}$ Bricker, Po'ot y Dzul (1998: 13) encuentran que el primer significado es 'papa dulce', mientras que otro significado refiere a 'vagina'.

${ }^{11}[I z]$ es el término registrado en buena parte de las fuentes coloniales para referirse a 'batatas o camotes', a saber: Bocabulario de Maya Than o de Viena [batata o camote: iz] (Acuña, 1993: 140); Diccionario de San Francisco: [iz: batata, camote]; Diccionario Maya de Motul (Ciudad Real, 1929: 460) [iz: batatas o camotes; son buenas de comer. casi tienen sabor de castañas]; diccionario de Pío Pérez (1898: 38) [iz: riñon, camote]; Diccionario de Viena [iz: Batata o camote: iz. Bengo a comprar camotes:
} 
En la Tabla 1 observamos que las formas léxicas para 〈yuca〉 muestran reflejos del término reconstruido en protomaya para nombrar a Manihot esculenta * $\phi^{\prime}$ iin o * ¿ihn; es decir, todos son lexemas claramente cognados y, por lo tanto, la reconstrucción linguiística del protonombre no presenta conflictos —véase su distribución geográfica en el Mapa 1-. Se aprecia que en huasteco se agregó el morfema reconstruido por Kaufman y Justeson (2003: 1090) como *tyee, pero el resultado

ah mani izen] (Acuña,1993: 140). En el Arte de el idioma maya de Beltrán de Santa Rosa (1746: 179), la Coordinación alfabética de las voces del idioma maya de Pío Pérez (1898: 38), de Swadesh, Ávarez y Bastarrachea (1970: 50) y de Ermilo Solís (1949: 112; 505) está una entrada léxica homófona que refiere a 'riñón'. Pese a que esta última es homófona con la raíz para 'camote' no se pueden considerar semánticamente relacionadas, excepto por una posible motivación en cuanto a la forma irregular que ambos tienen. En ninguna de las otras lenguas (huasteco, chontal y ch'ol) se encontraron referencias al uso del mismo término para 'riñón' y para 'camote'.

12 Bricker, Po'ot y Dzul (1998: 51) la traducen como 'yuca' y agregan que es 'a large herbaceous plant with edible root'. La alternancia entre $\mathrm{la} / \mathrm{m} / \mathrm{y}$ la $/ \mathrm{n} /$ finales evidenciada en las formas registradas tiene que ver con una regla del maya yucateco donde las nasales finales se labializan en ese contexto (n --> m/_\#).

${ }^{13}$ Documentado en la Coordinación alfabética de las voces del idioma maya de Pio Pérez (1898: 100) [jiin: yuca]; Diccionario de Motul (1929: 285) [jin: yuca, de donde se haze el caçave]; Calepino Maya de Motul fol. 131v (Arzápalo, 1995: 1639) [jin: yuca. de donde se haze el cacave]; en las Relaciones histórico-geográficas de la Gobernación de Yucatán (1983, I: 263): "Los nativos de esta provincia tienen ciertas raíces que ellos plantan y crecen en la tierra para su alimento. Estos son producidos en el invierno. Ellos lo llaman Yz, que son papas, y Dzin, que es la yuca dulce".

${ }^{14}$ En huasteco hay otra especie de camote que se llama lab $i \theta$, "camote real, pero corresponde a Dioscorea remotiflora, que también se conoce en español como camote de cerro". No existen referencias coloniales para camote o yuca en huasteco; solo contamos con los registros actuales.

${ }^{15}$ Véase Kaufman y Justeson (2003: 1090).

${ }^{16}$ Las formas Pajkum y $\phi^{\prime}$ 'ihn reflejan nuestros registros fonológicos de ch'ol. Las alternancias ortográficas que se reflejan en la Tabla 1 para los mismos términos se explican por la variedad que existe en los registros hechos por los autores de las fuentes que consultamos. Es frecuente que tanto la glotal /// como la aspirada /h/ sean subrepresentadas en los registros con alfabeto normalizado así que es posible que se trate solo de variación ortográfica - aunque no podemos asegurarlo, pues el registro es de otros autores-. En cuanto a la pérdida de la aspiración que contrasta entre los registros del chıol con respecto a los del chontal, uno de nuestros dictaminadores nos hizo notar que la pérdida de aspiración vocálica antes de las velares en chontal parece ser irregular, y que puede ser interpretada como préstamo. En todo caso, se prefirió respetar las grafías de cada autor para tener el dato idéntico según se representó en cada caso.

${ }^{17}$ Aulie y Aulie, 1996: 30.

${ }^{18}$ Becerra y Berlin, 2008: 9.

${ }^{19}$ Kaufman y Justeson, 2003: 1089.

${ }^{20}$ Aulie y Aulie, 1996: 122.

${ }^{21}$ Becerra y Berlin, 2008: 44.

22 Keller y Luciano, 1997: 3.

${ }^{23}$ Keller y Luciano, 1997: 263.

${ }^{24} \mathrm{Si}$ bien el término 'camote' puede tener el significado de 'tubérculo genérico' en contextos de habla no especializada, en este caso tenemos la certeza de que las formas mayas presentadas en la Tabla 1 reflejan el significado preciso de Ipomoea batatas y Manihot esculenta respectivamente, pues la elicitación se hizo con el tubérculo en cuestión (o bien, una imagen de este) frente al hablante. Por otro lado, varios de los diccionarios consultados tienen en la entrada una referencia a su nombre científico; en caso de no tenerlo, la transparencia en la forma léxica registrada garantiza que se trata del mismo referente y no de un término genérico para tubérculos. 
actual es una forma lexicalizada en huasteco que alterna regionalmente como t'inče? en la variante de SLP, con čisin, en huasteco de Chinampa de Gorostiza, Veracruz.

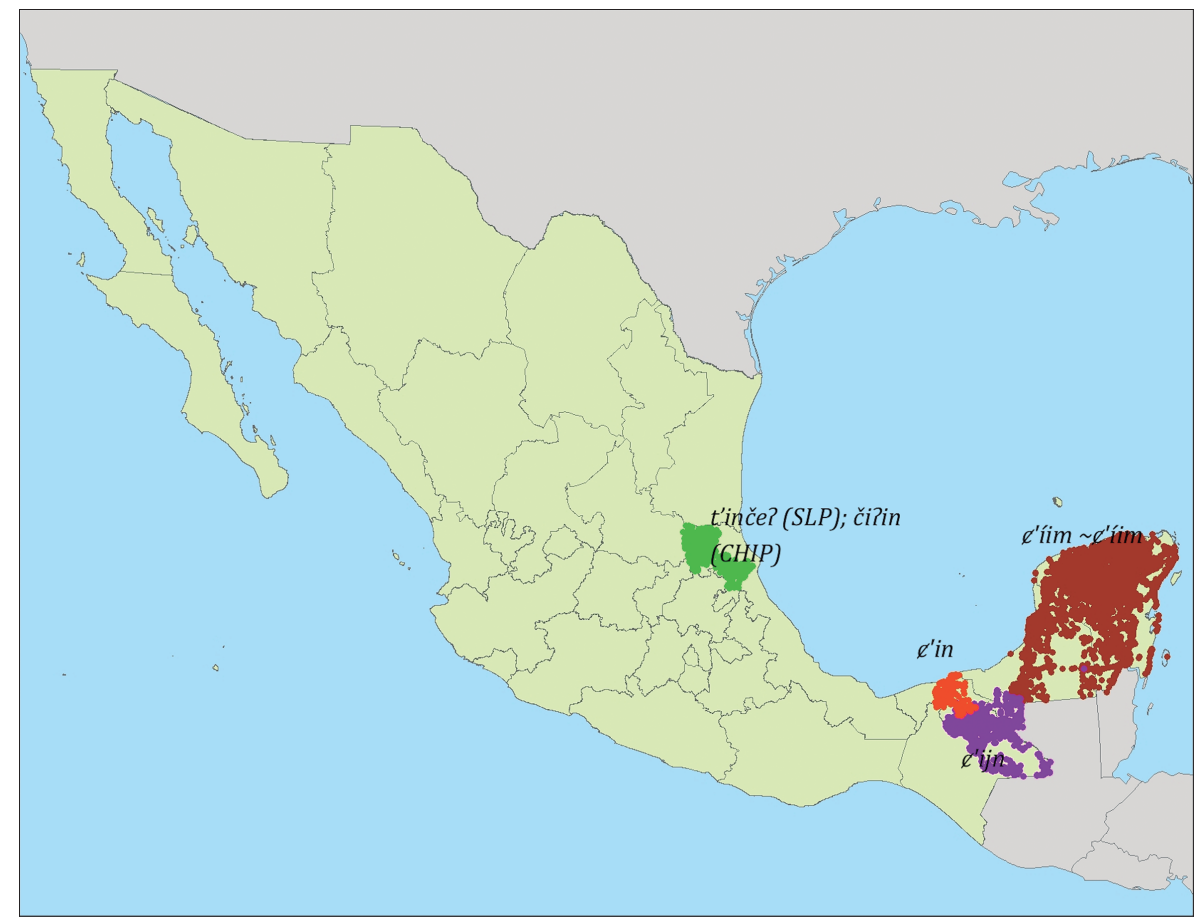

Mapa 1. Distribución de los términos para “yuca” entre ch〉oles, chontales, yucatecos y huastecos. Mapa: Oscar Zamora.

Por otro lado, el término Pis en casi todas las lenguas mayas es claramente rastreable y reconstruible hasta el protomaya *2iis con el significado primario de "camote" o "sweet potato" (Ipomoea batatas) (véase Kaufman y Justeson, 2003: 1089-90, 1134, así como nuestros propios datos de campo). Por tratarse de un tubérculo, el término Pis se extendió semánticamente también a la papa (Solanum tuberosum), una vez que ésta se introdujo a Mesoamérica en un periodo post-conquista, ${ }^{25}$ como consta en las traducciones para muchas lenguas mayas presentadas por Kaufman y Justeson (2003: 1134) en su diccionario etimológico.

Por su parte, en diccionarios modernos de ch'ol y chontal consultados, así como los datos de ch`ol recolectados por Trabanino y Meléndez (2017) y los propios, muestran el reemplazo léxico del término Pis por ?ajkum entre los ch'oles,

${ }^{25}$ La papa no era un tubérculo de cultivo vernáculo entre los mayas, se introdujo con la expansión de los españoles traído de la región andina. 
o bien, por ?akum entre los chontales, para referirse al tubérculo de Ipomoea batatas. Este reemplazo léxico es presumiblemente reciente, pues si bien está documentado en múltiples diccionarios de principios del siglo xx, una referencia epigráfica (prehispánica) hallada por Beliaev, Davletshin y Tokovinine (2009) refleja una forma relacionada con Pis (en el Mapa 2 se presenta la distribución actual de los términos atestiguados).

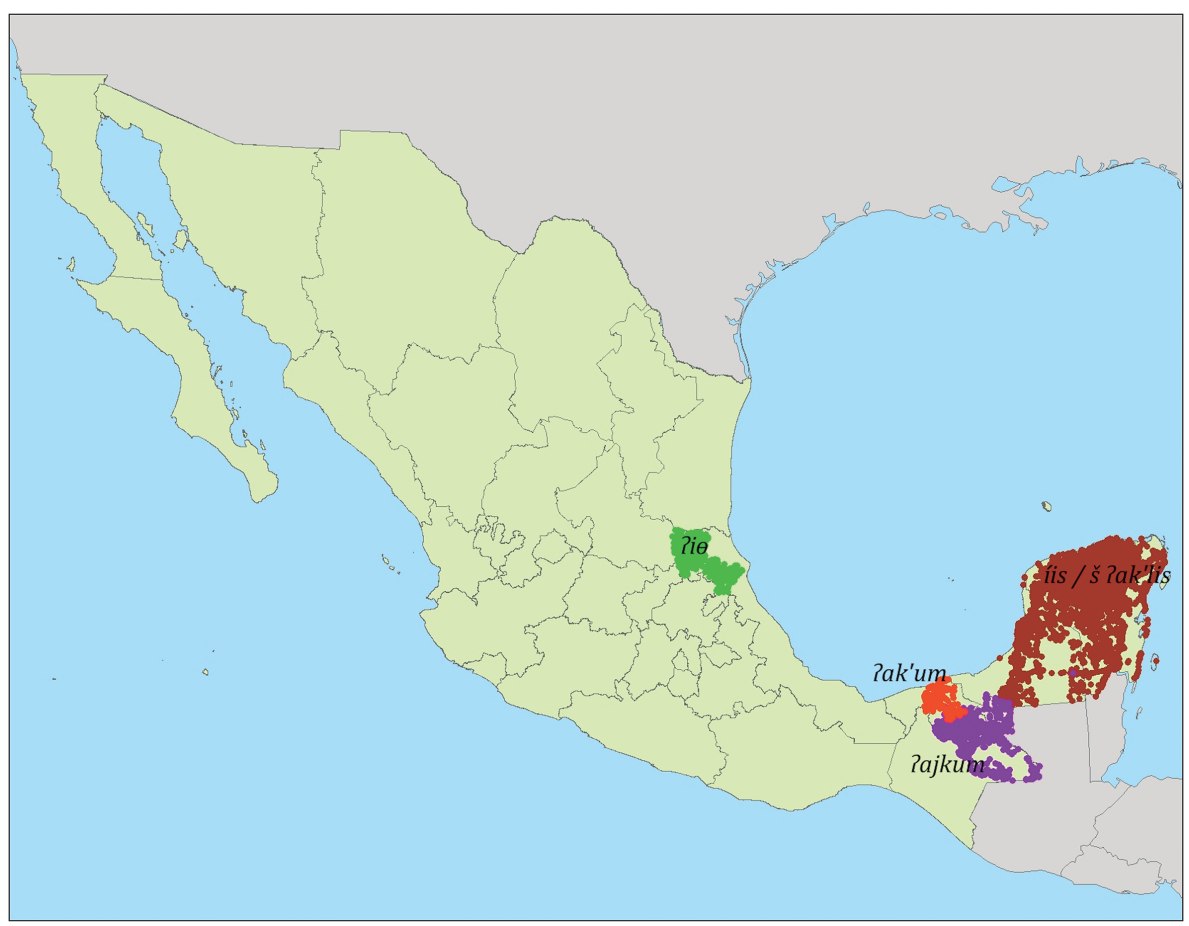

Mapa 2. Distribución de los términos para “camote” entre ch’oles, chontales, yucatecos y huastecos. Mapa: Oscar Zamora.

Los términos ?ajkum o ?akum resultan poco transparentes en cuanto a su etimología, ${ }^{26}$ pues no están atestiguados cognados con el significado de "camote" con esta misma forma en otras lenguas mayas distintas al ch'ol y al chontal, y llama la atención que la innovación léxica está presente solo en las lenguas chıolanas occidentales y no en las orientales, pues en ch'orti' y en ch'oltí se utili-

26 Uno de nuestros dictaminadores nos señaló que la lengua ch'orti tiene la palabra $k u$ 'm para "testículo, huevo, o cualquier fruta larga u ovalada", lo que podría estar relacionado con ajkum/ akum, donde aj-kum, podría tener una traducción aproximada de "lo de la forma del huevo". Este podría ser un origen viable para este término, el cual pudo haber sido introducido como préstamo o bien, también puede explicarse como una estrategia común morfológica en varias lenguas mayas donde se combina el morfema aj con otras raíces para derivar nuevos ítems. 
zan reflejos de *iis para designar a Ipomoea batatas. ${ }^{27}$ Tanto Pajkum como Pakum son palabras estructuralmente complejas ya que reflejan una estructura silábica CVC.CVC o bien, una CV.CVC, que a su vez tienden a representar palabras compuestas por más de un morfema en las lenguas mayas. ${ }^{28}$ Dado que las posibles segmentaciones morfológicas de estos ítems nos pueden conducir a diversos caminos poco relevantes para nuestro estudio, por ahora basta concluir que en la actualidad tanto Pakum como Pajkum son unidades léxicas que codifican el significado de "camote" en cada una de estas lenguas, son lexemas claramente cognados entre sí pero divergentes del término reconstruido como *?iis, lo que las convierte en formas léxicas innovadoras dentro de la familia linguiística maya.

Además de los términos básicos atestiguados, existen otros términos que se relacionan con variantes específicas de tubérculos asociados al camote y a la yuca, pero son claramente palabras compuestas a partir de los términos básicos, como se resume en la Tabla 2. Lo que refleja son tipos y subtipos de tubérculos que no serán estudiados en sus particularidades pero que dan cuenta de la diversidad de términos que hay y que linguísticamente se están distinguiendo en cada uno de los grupos estudiados.

\begin{tabular}{|c|c|}
\hline Nombre maya & Traducción libre \\
\hline xkubaana iis (yuc) & camote cubanita \\
\hline chak iis (yuc) & camote rojo \\
\hline sak iis (yuc) & camote blanco \\
\hline xmóorado iis (yuc) & camote morado \\
\hline k'an iis (yuc) & camote amarillo \\
\hline ak'iil ts'ím (yuc) & yuca trepador \\
\hline k'an ts'ím (yuc) & yuca amarilla \\
\hline sak ts'ím (yuc) & yuca blanca \\
\hline 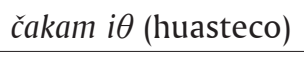 & camotito \\
\hline lab i $\theta$ (huasteco) & camote real \\
\hline lek i $\theta$ (huasteco) & camote pequeño colorado \\
\hline
\end{tabular}

Tabla 2. Nombres de tipos específicos de camote y yuca derivados de las formas léxicas básicas.

A partir del análisis linguiístico de los términos atestiguados se confirma que tales tubérculos tuvieron un significado cultural sustancial para los hablantes de

27 El término yucateco š Pak'lis registrado por Bricker, Po'ot y Dzul (1998) que también refiere a “camote", podría estar parcialmente asociado a la forma atestiguada en las lenguas ch〉olanas occidentales, pero está combinado con otros morfemas, así que tampoco es clara su relación.

${ }^{28}$ Las raíces tienen una estructura predominantemente CVC, mientras que los afijos tienden a tener una estructura silábica CV- o -VC. 
estas lenguas pues la presencia de raíces prototípicamente mayas cognadas y claramente reconstruibles hasta la protolengua nos habla de un conocimiento y manejo ancestral de dichos cultivos por parte de estos tres grupos. Hay que resaltar la distancia geográfica y linguística que existe entre los huastecos (te:nek) y los mayas de las tierras bajas (ch'olanos y yucatecanos), pues es significativo que, pese a la divergencia linguística y cultural que actualmente existe entre los huastecos y los otros dos grupos, en todos se reflejan formas cognadas.

Este hecho linguístico confirma lo que a su vez se había postulado desde el campo de la arqueología acerca de que entre los mayas prehispánicos los tubérculos fueron conocidos, cultivados y consumidos de distintas formas y bajo diferentes circunstancias sociales (Bronson, 1966; Isendahl, 2011; Pohl et al., 1996; Pope et al., 2001; Sheets et al., 2011). Esta práctica cultural claramente continuó vigente durante la colonia y prevalece hasta la época actual, donde siguen fungiendo como alimentos complementarios de la dieta diaria así como víveres de reserva (Landa, 1994; García Quintanilla, 2000).

\section{El uso del camote y la yuca en la cocina maya}

A partir de evidencia arqueobotánica, epigráfica, de fuentes coloniales y de datos de campo actuales es posible afirmar que el camote fue y sigue siendo un ingrediente profusamente usado para elaborar diferentes bebidas y alimentos tanto dulces como salados entre los mayas. Se consumía ya sea solo o mezclado con maíz. La mezcla de maíz con otros ingredientes para hacer tortillas, bebidas o algún otro tipo de alimento parece haber sido una práctica común entre los mayas prehispánicos, pues se ha encontrado evidencia de mezclas de maíz con ramón (Fernández Souza y Matos, 2014) ${ }^{29}$ así como de maíz con camote (Trabanino y Meléndez, 2017; Beliaev, Davletshin y Tokovinine, 2009).

Actualmente, entre los mayas yucatecos, los ch'oles y los te:nek (o huastecos), el consumo de tubérculos sigue teniendo una presencia importante en la cocina, ya que hemos documentado una diversidad de formas en su preparación que van desde la simple cocción en agua o al vapor, guisos en forma salada, cocinados con azúcar, miel o piloncillo, ${ }^{30}$ pero también mezclados con maíz para elaborar diferentes tipos de bebidas e incluso mezclado con la masa para elaborar tortillas (Lasso y Trabanino, 2015; Ferrer, 1999; Terán, Rasmussen y May, 1998).

${ }^{29}$ Fernández y Matos (2014: 91) mencionan el hallazgo arqueológico en un mortero de maíz mezclado con ramón, posiblemente para elaborar tortillas, pues ésta es una práctica vigente entre los mayas yucatecos. De acuerdo con Long y Vargas (2005: 11) las semillas de ramón, igual que los tubérculos, eran alimentos complementarios en la dieta de los mayas prehispánicos cuando había escasez de maíz.

30 El piloncillo o panela no es un producto prehispánico sino que fue introducido como endulzante en un periodo posterior a la Conquista en algunas regiones de lo que hoy es México. Es un producto procesado a partir del jugo de la caña de azúcar y que los huastecos aprendieron a elaborar desde que la caña se introdujo en la región en la primera mitad del siglo xvı (Aguilar, 2010). Aunque 
La mezcla de maíz con camote en forma de bebidas entre los ch〉olanos está atestiguada desde la época prehispánica a través de evidencia epigráfica (Beliaev, Davletshin y Tokovinine, 2009) y arqueobotánica (Trabanino y Meléndez, 2017), lo que da cuenta de la profundidad temporal en el uso de estos ingredientes en la cocina maya con prácticas culinarias similares.

Beliaev, Davletshin y Tokovinine (2009: 264) encontraron el registro epigráfico del texto: 'i-si 'u-lu o 'is 'ul, "atole con camote", inscrito en una vasija de procedencia desconocida ubicada en el museo de Santo Domingo, en Antigua, Guatemala, en lo que ellos describieron como "a previously unknown kind of Classic Maya mixed drink". ${ }^{31}$ El estudio de Trabanino y Meléndez (2017), en torno a los residuos de camote y maíz hallados en un cajete del sitio arqueológico de Chinikihá, Chiapas, confirma la idea de que los mayas de las Tierras Bajas elaboraban mezclas de maíz con camote para preparar, ya sea la bebida referida por Beliaev, Davletshin y Tokovinine (2009), o bien alguna otra bebida similar, pues identificaron ambos ingredientes dentro del mismo objeto arqueológico.

Como muestra de la continuidad en las preferencias de consumo, entre los ch〉oles actuales de los alrededores de Palenque, Trabanino y Meléndez (2017) encontraron el consumo regular de la bebida ?ajkum sa?, traducida libremente por los hablantes como "pozol de camote". Por su parte, Poot-Matu et al. (2002: $65)^{32}$ también han encontrado que, entre los habitantes de comunidades rurales de Tabasco, específicamente en Macuspana, donde habitan hablantes de chontal de Tabasco, se mezcla el camote con maíz para elaborar una bebida denominada pozol y también "como tortilla (mezclado con maíz)".

Varios registros coloniales de maya yucateco dan cuenta de la continuidad de dichas prácticas culinarias, pues están ampliamente documentadas distintas bebidas y alimentos con yuca y camote entre sus ingredientes principales. ${ }^{33}$ Se tienen

es probable que los huastecos usaran la miel como endulzante durante la época prehispánica, o algún otro edulcorante derivado del agave, por ejemplo, por ahora no tenemos certeza de ello. En el estudio sobre la dieta arcaica mesoamericana llevado a cabo en el occidente de Mesoamérica, Zizumbo, Flores y Colunga (2012: 336) proponen que desde épocas muy remotas se usó el almíbar o jarabe de mezcal (Agave ssp.) como endulzante: "the results of this research suggest that agaves, together with maize, constitued the center of the archaic diet in Western Mesoamerica...". Sin embargo, en la actualidad —y desde la época colonial—, los huastecos no son productores de miel ni de agave, sino más bien se especializaron en la producción de endulzantes derivados de la caña como la "panela" o piloncillo, por lo que la forma de endulzar es primordialmente con este ingrediente, o en su caso, con el azúcar que compran. Por ahora no podemos asegurar que también hubiesen utilizado el jarabe de agave como endulzante pero tampoco se debe negar esa posibilidad.

${ }^{31}$ En su trabajo sugieren que el tipo de vasija; asociado al contenido que refiere a sa' y 'ul respectivamente; puede tener relación con el tipo de consistencia y/o temperatura del atole con camote, mismo que era diferente de un atole genérico (Beliaev, Davtletshin y Tokovinine, 2009: 264).

${ }^{32}$ Los autores han encontrado que en Tabasco, zona primordialmente de ocupación chontalana y chıolana durante las épocas prehispánica y colonial, el cultivo y consumo de los tubérculos es una práctica de subsistencia importante pues ayuda a complementar la dieta, enriqueciéndola con otro tipo de nutrientes que no se encuentran en el frijol y el maíz.

${ }^{33}$ Lamentablemente, los escasos registros coloniales de huasteco y de lenguas ch'olanas occidentales no contienen información culinaria sobre los tubérculos que estamos estudiando. 
registros de yucateco en donde se refiere a la mezcla del camote con maíz para elaborar diversos tipos de bebidas así como alimentos sólidos: sa is ul, "atole de maíz nuevo, hecho el mismo día o con camote molido” (Barrera Vázquez, 1980: 707). En el Calepino Maya de Motul (siglo xvı, f. 82v) ${ }^{34}$ aparece la entrada Coppen, traducida como "puchas o atol azedo y sabroso echo de maiz viejo con mezcla de batatas”. De acuerdo con Bolles (2001: 2716), en la Coordinación alfabética de las voces del idioma de Juan Pío Pérez, también está documentada la entrada "izil $z a$ atole de camotes ó batatas”. El compendio de Pío Pérez se refiere también a un "guiso de camote", que se adereza con la planta Itzinte.

Para la época actual, Ferrer (1999: 34) documentó la receta de isi sa', "atole con camote", entre los mayas de Quintana Roo. Bricker, Po'ot y Dzul (1998: 13) documentaron la entrada $\check{S}$ Ṕísil, "sweet potato patch [parte del camote]" y "slug [babosa]". En la misma página están las entradas $\check{s}$ Pisi?-sa? para "atole hecho de maíz y papa dulce", y Pis-úul para "atole hecho de maíz verde con un poco de sal". Llama la atención que a pesar de contener la raíz Pis, la segunda entrada no refiere a "camote".35

Con base en estos datos, es claro que la mezcla de maíz con camote para elaborar bebidas no es una práctica culinaria reciente, sino que forma parte de un continuum histórico que muestra una preferencia en su consumo al menos entre los yucatecos y los ch'olanos, pues de los huastecos no contamos con estudios descriptivos culinarios de ningún tipo realizados durante la Colonia.

En cuanto a la combinación con maíz en formato de alimento sólido, en el compendio de Pío Pérez (1898) está atestiguado is wah, "pan de maíz nuevo que aún está y sin secarse” (Barrera Vázquez, 1980: 271). Aunque la traducción no sugiere la combinación con camote, es clara la presencia del término is en esta entrada, por lo que el consumo en tal formato tiene continuidad al menos desde la época Colonial hasta nuestros días.

Recordando que la cocina abarca no solo la preparación sino también la comprensión de roles sociales de un determinado alimento en una cultura dada es preciso mencionar un contraste interesante en lo que se refiere al contexto de consumo del camote. La representación escrita de Pis en el nombre de la bebida que designa presumiblemente "atole de/con camote" en textos epigráficos mayas debe ser considerado como altamente relevante en términos culturales, pues la escritura solo fue usada para representar temas asociados a las élites mayas. ${ }^{36}$ De

\footnotetext{
34 En Arzápalo, 1995: 1562.

${ }^{35}$ Es posible que la relación se establezca a partir de las propiedades dulzonas que comparten el camote y el maíz verde o tierno.

${ }^{36}$ A pesar de que se trata de dos únicos registros epigráficos que refieren a Pis, su representación escrita no debe ser subestimada ni deja de ser significativa, pues algunos términos tienen una distribución temporal y geográfica muy limitada. Por otro lado, los temas favoritos en la escritura competen al ámbito religioso y político, mientras que aquellos que pertenece a la esfera de la comida representa un porcentaje mínimo dentro de los textos jeroglíficos mayas. En la esfera de los alimentos también hay una tendencia predominante a representar textos relacionados con el referente "cacao" por su relevancia cultural, y hay una bajísima proporción de otros términos asociados a alimentos y bebidas.
} 
tal suerte que podemos inferir que los textos epigráficos que refieren a alimentos procesados sólidos o líquidos consumidos en recipientes de tipo utilitario necesariamente tuvieron algún tipo de prestigio social. No es casualidad que la mayoría de los textos refieran al cacao como uno de los ingredientes principales de las vasijas cerámicas mayas.

En este contexto, la presencia inusual del texto $\mathrm{Pis} s a$ ? asociado a una bebida que mezclaba maíz con camote (Beliaev, Davletshin y Tokovinine, 2009) sugiere que pudo haber sido una bebida de prestigio, al menos entre los ch'olanos, grupo con el cual se relacionan los hallazgos arqueobotánicos de residuos de maíz con camote dentro de un mismo objeto (Trabanino y Meléndez, 2017).

En contraste, para la época actual, esta bebida está documentada principalmente en contextos de consumo cotidiano, pues no documentamos su presencia en ningún contexto de prestigio en ninguno de los grupos estudiados (celebraciones, rituales, etcétera), por lo que el patrón de consumo parece haber dado un giro a lo largo del tiempo.

En cuanto a las circunstancias bajo las cuales son consumidos los tubérculos en general, pero el camote y la yuca en particular, queda claro que existe una continuidad en los patrones culturales de consumo en cuanto alimentos de emergencia, tal como propuso Bronson (1966) para los mayas prehispánicos, documentado también por Landa (1994[1566]) durante la Colonia, y cuyas condiciones de consumo prevalecieron hasta épocas recientes entre los tres grupos estudiados, según registramos en los testimonios de nuestros consultantes (como también lo hizo García Quintanilla, 2000).

Procesos documentados en las prácticas culinarias

asociadas al camote y la yuca

Los procesos de cocción generalizados para los tres grupos del camote y la yuca que se han documentado son asados, hervidos en agua o cocidos al vapor y fritos. En las zonas rurales de Yucatán exclusivamente, algunas personas eventualmente consumen el camote cocido en horno de tierra (pib), ${ }^{37}$ lo que constituye una particularidad de los yuca tecos frente a los huastecos y los ch'oles, quienes usan el horno de tierra en mucho menor medida que los primeros.

Contextos actuales de consumo del camote y la yuca

En nuestras entrevistas encontramos que entre los tres grupos estudiados se refiere que el camote suele estar presente en las ofrendas de día de muertos. De

\footnotetext{
${ }^{37}$ De hecho, en el Diccionario Maya de Motul aparece bajo la entrada [mucbil: cosa que se encubre en tierra o sotierra o assa debaxo la ceniza o rescoldo. Mucbil iz, batatas assadas assi] (Ciudad Real, 1929: 635).
} 
acuerdo con el testimonio de un milpero de Xocén recolectado por García Quintanilla (2000: 272), el camote se consume durante la cuaresma en sustitución de la carne y es considerado como un alimento sagrado; sin embargo, esta referencia al consumo con carga simbólica sagrada no parece ser evidente entre los huastecos y los ch'oles, quienes lo consumen de manera regular en su vida cotidiana.

\section{Recetas actuales}

Entre las recetas de cocina yucateca en el ámbito de los postres, encontramos el camote cocinado con canela y azúcar para elaborar dulce de camote, o bien como atropellado de camote con coco, en el que "se hierve el camote, desmenuza y posteriormente se mezcla con azúcar, coco y canela". ${ }^{38}$ También registramos referencias a que se cocina mezclado con harina de trigo para hacer pastelitos de camote, buñuelos de camote con plátano, así como empanadas rellenas de camote hervido.

Se le consume como ingrediente de un guiso conocido como "puchero", al que se añade entero y pelado junto con otras verduras como papa, zanahoria y chayote. También es frecuente que se use en lugar de la papa. En Tixcacalcupul y en Hunukú nuestros consultantes refirieron que el camote suele ser acompañante sólido del atole de masa blanca salado; en lugar de comer pan, se consume el camote simplemente hervido, o bien cocido en pib. En su uso más reciente, también se fríe en rebanadas delgadas como tostadas. Barros y Buenrostro (2002: 16) citan entre sus recetas de cocina en Tabasco el "camote con guanábana", que se hace mezclando estos dos ingredientes con azúcar y agua, un dulce que es servido en hoja de maíz.

Una particularidad en las preferencias de consumo entre los yucatecos que contrasta con las de los huastecos es la tendencia a endulzar el camote y la yuca con miel, en lugar de azúcar o piloncillo. Esto tiene una explicación cultural, pues los yucatecos se han especializado desde épocas prehispánicas como apicultores, según consta en el Códice de Madrid en la sección relacionada con la recolección de miel de melipona, lo que marca esta tendencia en su uso dentro del ámbito culinario. ${ }^{39}$

Por su parte, y de acuerdo con Aguilar (2010: 83), la caña de azúcar fue introducida desde 1523 en la región de la Huasteca potosina, y su procesamiento en formato de piloncillo ha sido una práctica arraigada entre la población te:nek desde entonces, lo que explica su preferencia por endulzar el camote con derivados de caña, ya sea el piloncillo o el azúcar misma.

\footnotetext{
${ }^{38}$ Véase Irigoyen, 2003: 58-59.

${ }^{39}$ Uno de los dictaminadores nos cuestionó acerca de la posibilidad de que ésta pudiese ser influencia de una práctica poblana con origen mestizo; sin embargo, nuestro argumento radica en que los mayas yucatecos poseen una larga tradición en el uso de la miel como endulzante para alimentos y bebidas atestiguada desde la época prehispánica, lo que hace altamente probable que su uso como endulzante sea resultado de la continuidad de una tradición propia antigua.
} 
Entre los te:nek, el camote se consume principalmente como dulce de camote, hervido con o sin azúcar o piloncillo; la conserva de camote es una forma particular y frecuente entre este grupo de procesar el tubérculo. Los entrevistados también declararon consumirlo en empanadas hechas a base de harina de trigo, pero rellenas de camote. En solo dos de las nueve comunidades te:nek estudiadas se refiere un uso salado del camote en guisos: en San Antonio Huitzquilico, nuestro consultante refirió un guiso de "camote morado con frijol, se le pone hoja de aguacate oloroso"; mientras que en Tamaletom, San Luis Potosí, también se incorpora a guisados con carne de puerco o de res.

Entre los huastecos actuales, el camote está atestiguado como alimento complementario. También tenemos registro de su uso como alimento de "emergencia”, ${ }^{40}$ pues dos de nuestros consultantes de los municipios de Tantoyuca y Chontla, Veracruz, respectivamente, refirieron a que en alguna ocasión una sequía intensa azotó la región, ocasionando escasez de maíz, lo que obligó a que mezclaran el maíz con el camote para hacer tortillas. ${ }^{41}$ Esta mezcla también fue enunciada en San Antonio Hutizquilico, San Luis Potosí, para hacer "tortilla de camote" o bien bok'oles ${ }^{42}$ de camote, pero acotaron que ya no forma parte de la cocina huasteca actual.

De manera interesante, y en contraste con los te:nek y los yucatecos, nuestros consultantes ch'oles declararon que el camote no se mezcla con otras cosas que no sea el pozol. ${ }^{43}$ Se puede consumir simplemente hervido, pero no suele ser mezclado con ninguna clase de guisos. Tampoco suelen endulzarlo con ingredientes adicionales, pues lo consideran un producto con propiedades inherentemente dulces.

\footnotetext{
${ }^{40}$ Este uso no es raro en otras culturas pues está atestiguado también en Hawai'i como "alimento de emergencia" (Linares et al., 2008: 12): "el camote es una de las plantas sagradas conocida por los hawaianos como "uala, crece silvestre en las montañas y es consumida como alimento de emergencia". Bronson (1966) ya había advertido también esta función entre los mayas prehispánicos de la región de Tikal, en el Petén guatemalteco.

${ }^{41}$ La práctica de mezclar maíz con camote para hacer tortillas está atestiguada asimismo entre los huaves actuales, ikoots (Samuel Herrera, comunicación personal), como un alimento de la vida cotidiana (aunque las tortillas son distintas de las que se conocen entre los mayas, pues son gruesas y horneadas, no cocidas en comal). Según los datos de campo de Samuel Herrera, además de mezclar el maíz con camote, los huaves también lo mezclan con plátano o con frijoles para hacer variaciones en la tortilla. Por su parte, uno de los dictaminadores nos indicó que también entre los zapotecos del Istmo se hacen tortillas de maíz con camote en contextos cotidianos, no como alimento de emergencia. Esta práctica compartida entre ambos grupos puede ser producto de influencia mutua, pues históricamente conviven en la región desde hace mucho tiempo. Habrá de indagarse en un futuro si la práctica de mezclar el camote con maíz para hacer tortillas es algo común a otros zapotecos o bien a otros grupos fuera de esa región.

${ }^{42}$ Los bok'oles son gorditas de maíz mezclado con manteca de cerdo y comúnmente se les agrega frijol negro en bola, o incluso, una vez cocidos, pueden rellenarse con carne de cerdo o res. Es un platillo cotidiano entre los te:nek de San Luis Potosí y Tantoyuca.

${ }^{43}$ La mezcla del pozol con otros ingredientes para variar su sabor es una práctica común entre los ch'oles de la región de Palenque pues declararon que preparan pozol con jengibre, por ejemplo, e incluso elaboran pozol con makal o juk'.
} 
Por su parte, la yuca ${ }^{44}$ suele consumirse entre los mayas yucatecos cocida o "sancochada" con azúcar, o bien hervida o incluso frita y posteriormente aderezada con miel. Los yucatecos de Hunukú y Temozón producen de forma regular buñuelitos de yuca que son consumidos como postre cotidiano, pero que en especial en Hunukú se preparan para las fiestas de fin de año, como un platillo especial. También es frecuente que funja como sustituto de la papa, en el guiso conocido como kóol. Barros y Buenrostro (2011) encontraron que en Veracruz la cáscara de yuca puede mezclarse con otros ingredientes para formar una bebida llamada роро; ${ }^{45}$ sin embargo, este tipo de bebida no está atestiguada entre los mayas actuales ni coloniales.

Lasso y Trabanino encontraron que entre los ch'oles se consume ts'ijn waj, "tortillas con yuca", en las que se mezcla "la masa del maíz con la masa de yuca fermentada durante el mes de mayo, época de tumba y siembra en la región palencana en Chiapas" (2015: 119). Nuestros consultantes ch'oles refirieron que la yuca no se consume endulzada ni con miel ni con azúcar, y preferentemente acompaña a platillos salados.

Igual que el camote entre los huastecos y la referencia de García Quintanilla (2000) para los yucatecos de la región oriente de Yucatán, y aunque ya no es práctica común actual, la gente campesina de Yucatán y Quintana Roo (de los poblados estudiados) refiere que anteriormente la yuca se mezclaba con el maíz cuando éste escaseaba, amén de que los tubérculos en general eran sembrados para afrontar tiempos de escasez por bajas cosechas. Esto es referido particularmente por los campesinos de mayor edad de las comunidades, quienes a su vez mencionan que en general los tubérculos — camote (Ipomoea batatas), yuca (Manihot esculenta), sagú (Maranta arundinacea L.), ñame (Dioscorea alata L.), makal (Xantosoma yucatanense Engler), entre otros- eran sembrados como una estrategia para afrontar tiempos de hambre cuando había malas cosechas, mientras que algunos refieren que los tubérculos en general son beneficiosos para las milpas:

\footnotetext{
${ }^{44}$ En su trabajo sobre el léxico de la comida en Guatemala, Hjelleset (2010: 151) menciona una gran variedad en las formas de cocinar la yuca entre los distintos grupos mayas de dicho país. Es interesante que ella encontró una diversidad mucho más amplia con respecto a las formas de procesarla y consumirla de la que se ha atestiguado entre los grupos aquí estudiados. Encontró que los buñuelos de yuca se hacen solo en la región oriental de Guatemala, mientras que éstos se producen en varias comunidades de la región oriente de Yucatán. De hecho, la autora atribuye la presencia de los buñuelos de yuca a la región costa caribe y sugiere que junto con otros términos ubicados de forma exclusiva en dicha región, su distribución focalizada guarda relación con la cultura garífuna (ibid., 72).

${ }^{45}$ Esta bebida refrescante, que se consume en el área de Tlacotalpan, Veracruz, es muy refinada y nada pide a las espumas de la cocina contemporánea; el término es muy posiblemente de origen náhuatl, relacionado con la raíz apopozoquillotl, "espuma de agua” (Gran Diccionario Náhuatl, Molina, 1571: 7r). Sus ingredientes suelen ser cocolmeca, una planta trepadora (Smilax cordifolia), cacao, arroz, cáscara de yuca, raíz de chupipe, también una planta trepadora, y azúcar. Los ingredientes se muelen bien, para lograr una pasta que se bate con el molinillo hasta obtener una abundante espuma, que es lo que se servirá.
} 
porque se dice que son un buen amigo de los sembrados principalmente del maíz, que.... son un insecticida natural porque gracias a ellos los insectos no se acercan al maíz, se utilizan como una distracción (campesino de Kanxoc, comunicación personal).

De acuerdo con las recetas recolectadas por Ferrer (1999: 65, 70) entre los mayas de Quintana Roo, se menciona que los ñames voladores ${ }^{46}$ en caldo "lo acostumbraban los antiguos mayas, pero en la actualidad se consume poco" (ibid., 65); lo mismo para el ñame en pipián, sobre el que anota "ha perdido importancia en la preferencia de las familias" (ibid., 70).

Por su parte, entre los huastecos la yuca es de los alimentos más consumidos, ya que, de acuerdo con Cilia, Aradillas y Díaz (2015: 146-147), fueron de los más mencionados en su muestra por habitante de la comunidad de Tocoy, San Luis Potosí. En nuestro caso, documentamos su consumo en dulce y simplemente hervida, ambos en venta en el mercado de Tantoyuca, así como el consumo casero cotidiano en ambos formatos en las diversas comunidades donde recolectamos datos.

Finalmente, queremos destacar el patrón de consumo para endulzar el camote y la yuca entre los huastecos pues, en contraste con los yucatecos, los primeros no son productores de miel, pero sí de piloncillo, ingrediente que usan para endulzar bebidas y postres. Este hecho es culturalmente relevante, pues indica una tendencia de consumo actual marcada claramente por los ingredientes producidos por cada grupo.

Las tendencias culinarias de los huastecos y de los yucatecos favorecen un consumo dulce del camote y la yuca, mientras que los ch'oles no suelen consumir la yuca dulce, solo salada, y el camote no suele ser endulzado con ingredientes adicionales, pues es considerado un ingrediente con propiedades dulces. Ninguno de los tres grupos consume el pescado de forma regular; ante la pregunta expresa de si lo consumen con camote o con yuca, respondieron que ninguno de estos tubérculos forma parte de recetas que tienen el pescado como ingrediente principal.

Entre los tres grupos estudiados, el camote (Ipomoea batatas) suele consumirse solo (como una especie de pedazo de pan) simplemente hervido o, en su caso, endulzado con miel, azúcar o piloncillo; en los tres casos el camote puede ser el alimento principal en la cena o en el desayuno, acompañado de algún atole o de pozol; puede ser consumido como colación, o incluso como postre, pero no funge como el platillo central de la comida del medio día. Los huastecos y los yucatecos lo consumen como acompañante de guisos, en sustitución de la papa, y a veces, junto con la papa, mientras que los ch'oles no lo combinan con mezclas saladas.

${ }^{46}$ Cuando el autor habla del "ñame volador" no indica a qué especie se refiere, aunque por las características creemos que se trata de Dioscorea bulbífera $\mathrm{L}$. 


\begin{tabular}{|c|c|c|c|c|}
\hline & Huastecos & Yucatecos & Ch'oles & Chontales \\
\hline $\begin{array}{l}\text { Tipos } \\
\text { de cocción }\end{array}$ & $\begin{array}{l}\text { Asado, hervido, } \\
\text { cocido al vapor } \\
\text { y frito }\end{array}$ & $\begin{array}{l}\text { Asado, hervido, } \\
\text { frito y horneado } \\
\text { en pib }\end{array}$ & $\begin{array}{l}\text { Asado, hervido } \\
\text { y frito. }\end{array}$ & $\begin{array}{l}\text { Asado, hervido } \\
\text { y frito }\end{array}$ \\
\hline $\begin{array}{l}\text { Bebidas } \\
\text { de camote } \\
\text { con maíz } \\
\text { (Ipomoea } \\
\text { Batatas) } \\
\end{array}$ & $\begin{array}{l}\text { Documentado } \\
\text { solo en una } \\
\text { comunidad } \\
\text { de SLP47 }\end{array}$ & $\begin{array}{l}\text { Documentado } \\
\text { en la Colonia } \\
\text { y en la época } \\
\text { actual }\end{array}$ & $\begin{array}{l}\text { Documentado } \\
\text { en época } \\
\text { prehispánica, } \\
\text { colonial } \\
\text { y actual }\end{array}$ & $\begin{array}{l}\text { Documentado } \\
\text { época actual }\end{array}$ \\
\hline $\begin{array}{l}\text { Mezcla } \\
\text { de maíz con } \\
\text { camote para } \\
\text { elaborar } \\
\text { tortillas }\end{array}$ & $\begin{array}{l}\text { Documentado } \\
\text { en un pasado } \\
\text { reciente } \\
\text { (alrededor } \\
\text { de } 50 \text { años atrás } \\
\text { como alimento } \\
\text { de emergencia) }\end{array}$ & $\begin{array}{l}\text { Documentado } \\
\text { en época } \\
\text { colonial; también } \\
\text { en un pasado } \\
\text { reciente } \\
\text { (alrededor de } 50 \\
\text { años atrás como } \\
\text { alimento } \\
\text { de emergencia) }\end{array}$ & $\begin{array}{l}\text { No se hace } \\
\text { en la actualidad }\end{array}$ & $\begin{array}{l}\text { No documentado } \\
\text { por los autores }\end{array}$ \\
\hline $\begin{array}{l}\text { Mezcla } \\
\text { de maíz con } \\
\text { yuca }\end{array}$ & No documentado & $\begin{array}{l}\text { Documentado en } \\
\text { época colonial, } \\
\text { y en la memoria } \\
\text { de algunos } \\
\text { consultantes }\end{array}$ & $\begin{array}{l}\text { Documentado } \\
\text { en época } \\
\text { actual } \\
\text { como ts'ijn } \\
\text { waah }\end{array}$ & No documentado \\
\hline $\begin{array}{l}\text { Usos dulces } \\
\text { de la yuca }\end{array}$ & $\begin{array}{l}\text { Hervido } \\
\text { con piloncillo } \\
\text { o con azúcar }\end{array}$ & $\begin{array}{l}\text { Hervido } \\
\text { y endulzado con } \\
\text { miel o azúcar }\end{array}$ & $\begin{array}{l}\text { Nunca se hace } \\
\text { dulce de yuca }\end{array}$ & $\begin{array}{l}\text { Hervido } \\
\text { y endulzado } \\
\text { con azúcar }\end{array}$ \\
\hline $\begin{array}{l}\text { Usos } \\
\text { de la yuca } \\
\text { en guisos }\end{array}$ & No documentado & $\begin{array}{l}\text { Sí, es usado } \\
\text { frecuentemente } \\
\text { en guisos salados. }\end{array}$ & $\begin{array}{l}\text { Sí es usado } \\
\text { frecuentemente, } \\
\text { en caldo } \\
\text { de gallina, res } \\
\text { y puerco }\end{array}$ & ? \\
\hline $\begin{array}{l}\text { Usos } \\
\text { del camote } \\
\text { en guisos }\end{array}$ & $\begin{array}{l}\text { Sí, en Tamaletom } \\
\text { y en San Antonio } \\
\text { Huitzquilico, SLP } \\
\text { con guisos }\end{array}$ & $\begin{array}{l}\text { Sí, en puchero } \\
\text { con puerco }\end{array}$ & $\begin{array}{l}\text { No se usa con } \\
\text { guisos, solo con } \\
\text { pozol }\end{array}$ & ? \\
\hline $\begin{array}{l}\text { Presencia } \\
\text { en ofrendas } \\
\text { de día de } \\
\text { muertos }\end{array}$ & $\begin{array}{l}\text { Hervido, } \\
\text { endulzado } \\
\text { opcionalmente } \\
\text { con piloncillo } \\
\text { o con azúcar }\end{array}$ & $\begin{array}{l}\text { Hervido, } \\
\text { opcionalmente } \\
\text { endulzado } \\
\text { con miel }\end{array}$ & $\begin{array}{l}\text { Solo hervido } \\
\text { (no se agrega } \\
\text { endulzante) }\end{array}$ & $?$ \\
\hline
\end{tabular}

Tabla 3. Resumen comparativo de patrones de consumo de la yuca y el camote en la cocina maya

47 En San Franciso Chontla, Veracruz, y en Tamaletom, SLP, tres de nuestros consultantes declararon que sí lo consumen en atole, pero se refieren a otra especie de camote (lab Pi $\theta$, 'camote real') y no la que estamos describiendo en este trabajo. En Francisco Villa, San Vicente Tancuayalab, se refirieron a la bebida wat'ap ?i $\theta$, 'atole de camote', pero no podemos asegurar con certeza cuál de las especies utilizan para su elaboración. 
Ninguno de nuestros consultantes utiliza las hojas de Ipomoea batatas o de Manihot esculenta con fines alimenticios. ${ }^{48}$ Una de nuestras consultantes de maya yucateco (de Popolá, Yucatán) declaró que las hojas del kukut makal (Xantosoma yucatanense) son usadas para hacer tamalitos al vapor, sirven para envolver la masa de maíz, pero se trata de otras plantas de tubérculos, no las que estudiamos aquí.

Entre las particularidades para cada uno de los grupos encontramos que:

El camote en conserva solo lo preparan los huastecos;

a) La yuca y el camote endulzados con miel solo están documentados entre los yucatecos. La práctica de cocinarlos en pib es algo que también los particulariza.

b) El piloncillo para endulzar camote y yuca se ha documentado solamente entre los huastecos.

c) Los ch'oles tienen una clasificación del camote en el ámbito de lo dulce y la yuca pertenece a la esfera de lo salado. El camote no suele ser endulzado con algún otro ingrediente, pues se considera dulce por sí mismo.

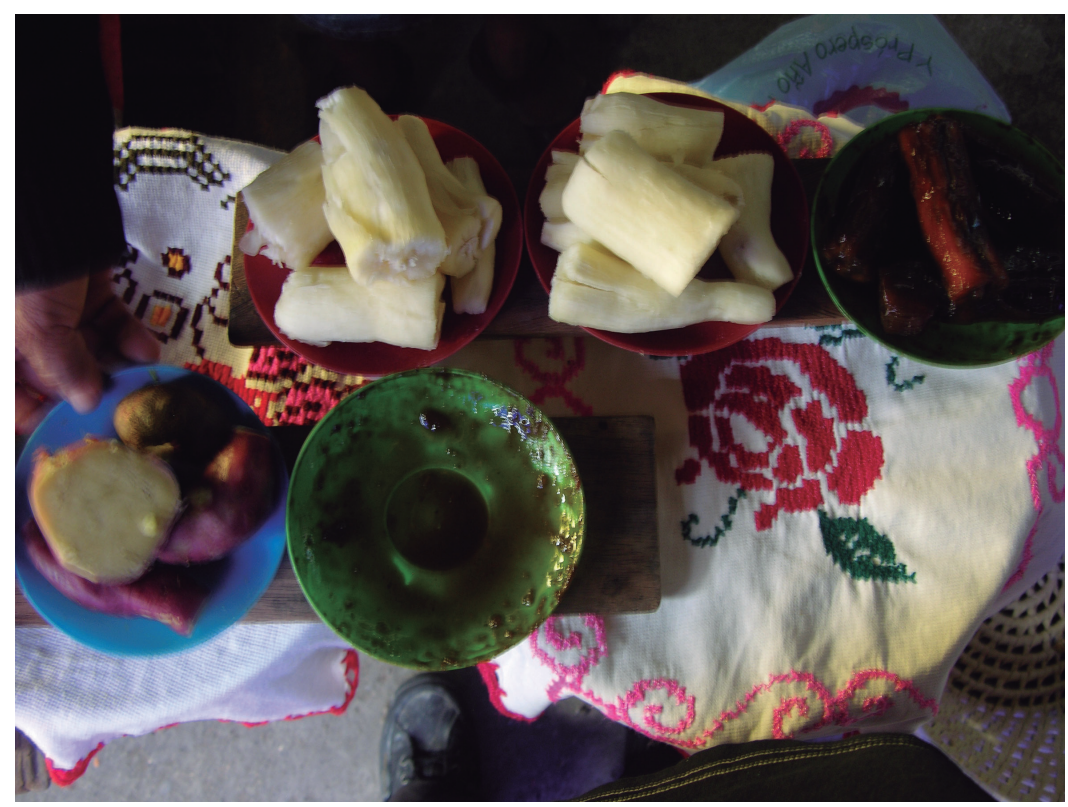

Figura 3. Venta de yuca hervida y yuca en dulce (mercado de Tantoyuca, Veracruz). Fotografía de Carla Tapia.

${ }^{48}$ Aunque sí documentamos su uso medicinal, como describiremos en el siguiente apartado. 


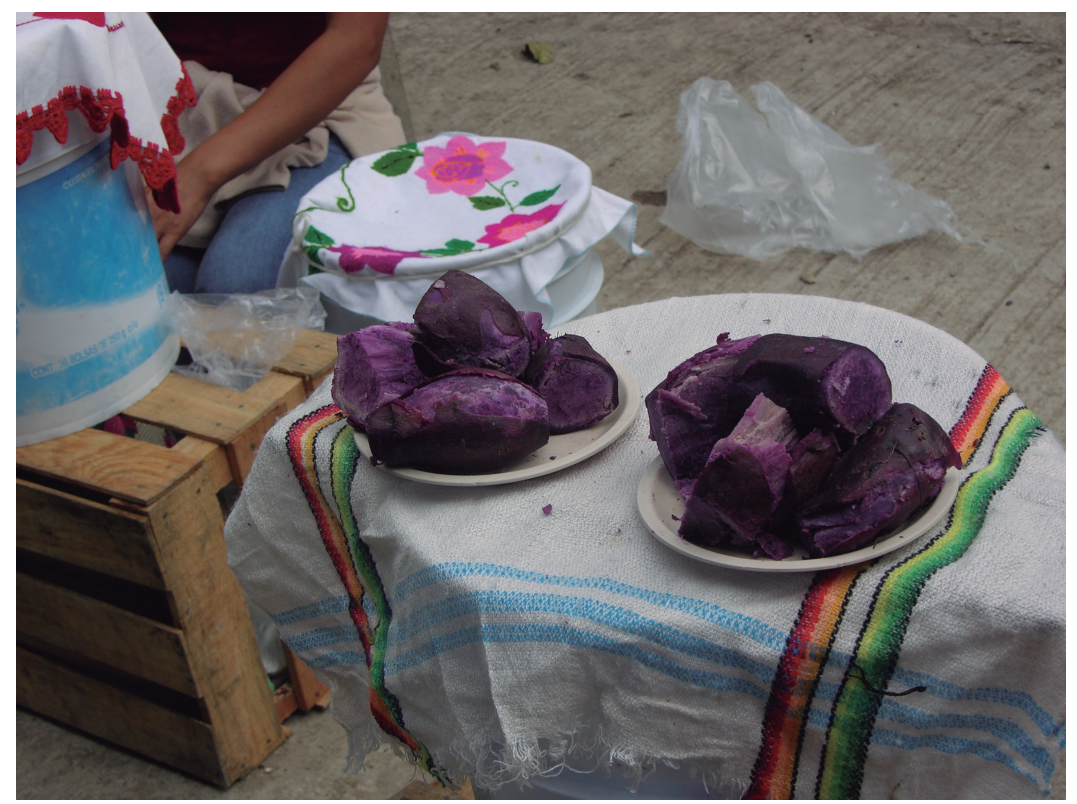

Figura 4. Venta de camote hervido.

Fotografía de Carla Tapia

\section{Usos rituales y medicinales del camote entre los yucatecos actuales}

En la literatura especializada, el camote y la yuca se reportan casi exclusivamente como productos para uso alimenticio y ocasionalmente medicinal; en este sentido, Linares et al. (2008: 12-13) hacen referencia a fray Juan de Navarro en su obra del siglo xix, Historia Natural o jardín americano, en la que se mencionan las propiedades medicinales del camote: "el camote es una fruta templada y que sirve de sustento; el agua en que se cuece es útil para bañar las manos gotosas".

Estos mismos autores mencionan que:

En general, los camotes se emplean como comestibles. Existen muy pocos reportes en los que se les atribuyen propiedades medicinales. Es el caso del camote amarillo que se menciona útil para el tratamiento de algunas enfermedades causadas por deficiencias nutrimentales como la pelagra y el escorbuto debido a la gran cantidad de vitaminas y de carotenos que contiene. De acuerdo a Lorenz y Matos, las hojas y raíces son efectivas para el tratamiento de leucemia, anemia, hipertensión, diabetes y hemorragias. En la medicina casera, según Roig y Mesa, el cocimiento de los bejucos se considera como galactagogo, es decir, sirve para aumentar la leche de las mujeres que están criando. Se han descrito las propiedades antitumorales a partir de decocciones de las hojas, que se utilizan en forma de gárgaras para tratar tumores de la boca y la garganta (ibid., 14). 
Encontramos otras referencias a tres especies de tubérculos con propiedades curativas: Dioscorea bulbifera L., conocida como la papa voladora o xbóolador makal, Dioscorea villosa o ñame silvestre y Manihot esculenta o yuca. Entre los mayas yucatecos actuales, la papa voladora es reconocida por sus propiedades depurativas del sistema urinario, para limpiar las vías renales y deshacer cálculos renales. Chevallier (1997: 89) señala que el ñame silvestre contiene diosgenina, una sustancia que "fue el punto de partida para la creación de la primera píldora anticonceptiva", y sus principales usos medicinales son como antiespasmódico, antiinflamatorio, antirreumático, sudorífico y diurético. En su trabajo afirma que

tanto los pueblos mayas como los aztecas utilizaron el ñame silvestre con fines medicinales, posiblemente para calmar el dolor.... En el norte y centro de América, el ñame silvestre constituye un remedio tradicional para las menstruaciones dolorosas, el dolor de ovarios y el parto (id.). ${ }^{49}$

En cuanto a la yuca, Chevalier (1997: 231) refiere que "la variedad amarga puede usarse para tratar sarna, diarrea y disentería".

En el presente estudio se encontraron cinco usos medicinales de Ipomoea batatas y Manihot esculenta, algunos comunes para ambas. ${ }^{50}$ En general para ambas especies —así como para los tubérculos en general-, los entrevistados hicieron referencia a su valor nutricional, ${ }^{51}$ por contener muchas "vitaminas", muy buenas para la salud, así como propiedades para depurar el organismo.

\footnotetext{
49 Justamente la sustancia que contiene la Dioscorea villosa ha sido aprovechada en algunos productos cosméticos actuales que son usados como tratamientos alternativos para la menopausia, pues la diosgenina es transformada por el cuerpo en progesterona natural.

${ }^{50}$ No hemos hecho pruebas para demostrar si las propiedades terapéuticas que se les atribuyen a los tubérculos aquí estudiados son efectivos o no. Simplemente referimos los testimonios de nuestros consultantes en torno a los usos que tradicionalmente tienen en este ámbito. Si bien tales datos provienen de la opinión subjetiva de los entrevistados, es sabido que la raíz de ambos tubérculos contiene considerables cantidades de almidón, vitaminas, fibras (celulosa y pectinas) y minerales, destacando el contenido de potasio (Linares et al., 2008; Padmaja, 2009). En valor energético supera a la papa y en vitaminas destaca por la provitamina A (betacaroteno), B1, C (ácido ascórbico) y E (tocoferol). De acuerdo con Linares et al. (2008: 15), "son una fuente valiosa de fibra, antioxidantes y rica en vitaminas y minerales... el tipo 'amarillo' tiene un contenido de beta-caroteno mayor que el de la zanahoria".

${ }^{51}$ De acuerdo con Thottappilly y Loebenstein (2009: 503-504), "el camote [sweet potato] contiene niveles sustanciales de proteína además de los carbohidratos. Estos proveen cantidades importantes de vitaminas y minerales... El camote es un alimento natural saludable por su alta energía, fibra dietética y contenido de vitaminas y minerales" [la traducción es nuestra]. Los autores reconocen que durante el procesamiento del camote se pierde una buena cantidad de los nutrientes, pero puntualizan que el consumo del tubérculo puede ser una solución para niños que manifiestan una deficiencia de vitamina A pues está contenida en altas cantidades en él (ibid., 505). Por su parte, Padmaja (2009) presenta una minuciosa descripción química sobre los nutrientes que se pierden o se conservan según el tipo de proceso que se aplique en la preparación del camote. En su análisis muestra que los camotes contienen carbohidratos (el nutriente primordial); polisácaridos sin almidón (celulosa, hemicelulosa y pectina, como fibra dietética), proteínas y aminoácidos, lípidos (en muy bajas cantidades), vitaminas (carotenoides, vitamina C, tiamina - B), rivoflabina - B2 y ácido pantoténico (ibid., 212-216).
} 
Uno de los usos medicinales referidos es para el mal olor del sudor de las personas o para la sudoración excesiva. Para esto se usa una decocción de hojas de camote, solas o combinadas con las de la yuca, con la que la persona que tiene este mal deberá bañarse de tres a cuatro veces.

Otro de los usos referidos es para bajar la fiebre, para lo cual se pueden utilizar ya sea las hojas del camote, hervidas y puestas en todo el cuerpo, o bien las hojas de la yuca, sin cocer, aplicadas directamente sobre la frente del enfermo el tiempo necesario hasta que baje la fiebre.

Para el camote también se encontró un uso en caso de heridas leves, se corta una tira delgada del mismo y se aplica amarrada sobre la herida.

Documentamos que, entre los huastecos de El Mamey, San Gabriel, Tantoyuca, existe una restricción para el consumo del camote en mujeres en periodo de lactancia, lo que nos habla de alguna propiedad negativa asociada al tubérculo, posiblemente porque puede provocar flatulencia en el bebé lactante.

El camote crudo no se consume, ya que, de acuerdo con Linares et al. (2008: 15),

puede producir flatulencia, diarreas e incluso una purgación drástica debido a su alto contenido de resinas glicosídicas (alrededor de 5 a 18\%), similares a las responsables de la actividad purgante de las especies del género Ipomoea que forman parte del complejo medicinal de la raíz de jalapa (Ipomoea purga e I. orizabensis, entre otras).

Los tubérculos y su presencia en el ámbito religioso maya

En el ámbito de la cosmovisión maya yucateca también se ha documentado su relevancia cultural ya que, al crecer dentro de la tierra, los tubérculos guardan una relación simbólica con el inframundo, y aquellos que han crecido en milpas abandonadas deben ser recogidos mediante rituales específicos descritos por García Quintanilla (2000). ${ }^{52}$

La importancia del camote en el ámbito de la religión maya no será abordada con profundidad, pues escapa a los objetivos de este trabajo, pero nos interesa destacar que el camote ha sido mencionado en algunos pasajes de textos rituales, como en el Chilam Balam de Chumayel, lo que da cuenta de su relevancia en el campo de la religión maya colonial.

El pedernal negro es la piedra del poniente. La Madre Ceiba Negra es su centro escondido. El maíz negro y acaracolado es su maíz. El camote de pezón negro es su camote. Los pavos negros son sus pavos. La negra noche es su casa (Chilam Balam de Chumayel, 1930: 17).

${ }^{52}$ En los testimonios referidos, se asegura que la hora para cortarse es a las 12 del día, porque de lo contrario, cuesta mucho trabajo encontrarlo. 
En la época actual, el camote sigue ocupando un lugar importante en la cosmovisión maya. El estudio de Vassallo (2016) es una muestra de ello, pues da cuenta de la presencia de este alimento en el campo de lo simbólico. En su trabajo refiere que un hmen de Xocén expresó que "el Chaak blanco, que vive por Cancún, trae lluvia blanca, es mala para el maíz, lo mata, pero es buena para que abunde el macal, ${ }^{53}$ las jícamas, los camotes, la yuca" (ibid., 128), lo que vincula los tubérculos con un tipo específico de lluvia, asociada al dios Chaak.

De igual forma, García Quintanilla (2000) destacó la importancia de los tubérculos entre los mayas yucatecos actuales y documentó algunos testimonios que los vinculan con el inframundo, dado que son alimentos que crecen debajo de la tierra. Retomando el texto de Villa Rojas (1978: 296 y 299), afirma que "los camotes no solo crecen bajo la tierra, camino del inframundo, sino que se siembran en sus entradas" (García Quintanilla, 2000: 273). En los testimonios que recolectó en Xocén, Yucatán, ${ }^{54}$ distingue dos tipos de tubérculos, los cultivados recientemente y aquellos que se encuentran en milpas abandonadas, convertidas prácticamente en monte, donde la vegetación es más alta y cuyos dueños ya no son los hombres sino Yum K'aax, el "señor del monte". De acuerdo con la autora, la recolección de estos últimos requiere la ejecución de un ritual, mismo para el que los mayas son preparados desde niños. Los tubérculos deben ser recolectados en punto de las 12 del día, cuando el sol está en su punto más álgido, y se requiere de una especie de amuleto - "pulsera"-, para ir en su búsqueda, pues son difíciles de hallar.

\section{Consideraciones finales}

El consumo con fines alimenticios de distintos tipos de camote entre diferentes grupos mayas es un hecho histórico bien documentado que nos ayuda a reconstruir patrones culinarios, así como entender parcialmente las prácticas subsistenciales de consumo entre los mayas prehispánicos, coloniales y actuales.

Los patrones de consumo hallados entre los distintos grupos mayas estudiados nos hablan de una continuidad cultural en el aprovechamiento de los recursos disponibles, así como de tendencias persistentes en la forma de elaborar y consumir los tubérculos. Es interesante destacar que mientras el consumo prehispánico quedó atestiguado entre las élites a través de los textos epigráficos que mencionan el término Pis, en la época actual no puede considerarse un insumo de prestigio; al contrario, entre los chontales, y como han advertido Poot-Matu et al. (2002: 61), en regiones de Tabasco, su uso actual está siendo relegado y marginado debido a que se ha priorizado el cultivo de cereales por encima de las especies de tubérculos tradicionales.

53 Se respetó la ortografía del autor, aunque en este trabajo se usa makal.

54 Y que comparó con los datos de Villa Rojas (mayas de Tusik, Quintana Roo). 
Por fortuna, entre los yucatecos, los ch'oles y los huastecos, los tubérculos siguen cultivándose y consumiéndose en diversas formas, lo que garantiza, al menos por un tiempo, la transmisión de prácticas culinarias antiguas que han sido reproducidas por siglos y que se están viendo amenazadas ante el avasallante avance de cultivos prioritarios para las grandes empresas, pero en detrimento de las dietas vernáculas locales. A partir de su presencia en la cocina maya podemos afirmar qué tubérculos forman parte de su identidad social en tanto que la preferencia en su consumo está mucho más marcada entre la población maya que entre los mestizos, siendo los primeros los que los cultivan, cosechan y consumen de forma habitual. ${ }^{55}$

Si bien los estudios más recientes de marcadores culturales asociados a los alimentos han estado vinculados al estudio de los restos animales (Guevara, Pichardo y Martínez, 2017; Fernández y Matos, 2014), es claro que los tubérculos jugaron y siguen jugando un papel importante entre los distintos grupos mayas, pues son un alimento de uso cotidiano atestiguado desde la época prehispánica que los identifica como grupo, en contraste con los grupos del centro, ${ }^{56}$ cuya cocina tiene una presencia predominante de otros insumos como los hongos, el epazote, los quelites, etcétera.

La mezcla de la yuca, el makal o el camote con la masa de maíz para elaborar bebidas, tortillas y tamales es una práctica de supervivencia heredada desde épocas antiguas que también está atestiguada en el siglo xx a través de los testimonios de los ancianos de las comunidades huastecas (te:nek) y yucatecas. El valor cultural de los tubérculos entre los grupos mayas estudiados radica en su uso como alimento complementario y de emergencia. Su consumo actual tiende a tener un estatus de alimento cotidiano entre los tres grupos mayas, pues se consigue de forma regular en los mercados locales y se consume a placer de los comensales.

Por su parte, la mezcla de camote con maíz para elaborar pozol con camote está documentada exclusivamente entre los ch'oles y chontales actuales. El registro

\footnotetext{
${ }^{55}$ En algunos supermercados de ciudades donde hay presencia de población maya (como Mérida, Valladolid, Villahermosa o Campeche) se pueden conseguir algunas variedades de tubérculos en la sección de productos locales. Sin embargo, la mayor diversidad de subespecies se encuentra en los mercados locales.

${ }^{56}$ El cultivo y consumo de Ipomoea batatas es relevante en muchos otros grupos de Mesoamérica además de los mayas, aunque nuestro énfasis se ha centrado en los patrones culinarios particulares a los mayas y que los distinguen de otros grupos. Por ejemplo, uno de nuestros dictaminadores nos hizo notar que su importancia como alimento de emergencia también ha sido atestiguado entre los huaves de San Mateo del Mar, donde Signorini et al. (1979: 54) lo ha descrito como un producto que “representaba una alternativa al maíz”. Igualmente, en Zizumbo y Colunga (1982: 110) se habla de un mito de origen entre los huaves en torno al camote, donde se destaca su valor como producto alimenticio complementario al maiz: “... con los camotes se llena bien la panza y el maíz ya no rinde con un grano sino que hay que usar más". Asimismo, nos señaló que entre los zapotecos del Istmo se consume de forma regular la tortilla mezclada con camote, no solo como alimento de emergencia, por lo que queda pendiente comprender el estatus de ambos tubérculos en un contexto mesoamericano más amplio.
} 
tanto prehispánico (ch'olano clásico) como colonial (yucateco) de bebidas que contienen camote mezclado con maíz no necesariamente corresponde a la bebida actual documentada entre los ch'olanos, pues no es lo mismo sa? que pozol. Aun cuando los procesos de elaboración posiblemente fueron diferentes, llama la atención que entre los ch'olanos occidentales se siga haciendo la misma mezcla de ingredientes para elaborar bebidas, lo que da cuenta de una continuidad en la cocina maya desde época prehispánica que se mantuvo en la Colonia y que continuó, al menos entre los ch'olanos occidentales, hasta la época actual.

Por ahora, no es posible tener certeza sobre si la práctica de endulzar el camote con miel haya sido un común denominador desde época prehispánica entre los diferentes grupos mayas estudiados; sin embargo, al ser históricamente productores de miel, es factible suponer que al menos los yucatecos sí lo hicieron desde entonces. Por otro lado, tampoco podemos asegurar con contundencia que todos compartieran la práctica de combinarlo con maíz para elaborar pozol/atole o tortillas, pues de los huastecos no hay registros coloniales ni prehispánicos al respecto sobre estos productos en particular; pero el dato epigráfico nos permite suponer que al menos los ch'oles, y posiblemente los chontales, sí lo hicieron desde época prehispánica. Por su parte, de las fuentes coloniales yucatecas se puede suponer que las prácticas registradas durante la Colonia temprana se remontan tiempo atrás, pues además los españoles las registraron como prácticas propias de los nativos, distintas de las suyas.

En el entramado cultural, y en el escenario del mestizaje gastronómico que han experimentado los distintos grupos indígenas del país, no es posible determinar con contundencia cuáles recetas son auténticas y exclusivamente vernáculas y cuáles son producto de difusión por contacto ya sea con el Viejo Mundo o con otros grupos mesoamericanos. Quedan muchas preguntas en el tintero, entre ellas comprender la influencia o contribución de las tradiciones de las Antillas, y específicamente de las tradiciones afrodescendientes, en el uso y consumo de los tubérculos, pero dejaremos esta y otras preguntas para trabajos futuros.

\section{Agradecimientos}

Los autores deseamos agradecer a los consultantes huastecos, mayas y ch'oles que participaron en nuestras entrevistas, así como a los estudiantes de la Licenciatura en Linguiística y Cultura Maya de la Universidad de Oriente, Yucatán. También agradecemos a los dos dictaminadores anónimos que hicieron sugerencias y comentarios que ayudaron a enriquecer este trabajo. 


\section{BIBLIOGRAFÍA}

Acuña, René (ed.)

1993 Bocabulario de Maya Than. Codex Vindobonensis N.S. 3833, Facsímil y transcripción crítica anotada. México: Universidad Nacional Autónoma de México, Instituto de Investigaciones Filológicas, Centro de Estudios Mayas, (Fuentes para el Estudio de la Cultura Maya, 10).

Aguilar Rivera, Noé

2010 "La caña de azúcar y sus derivados en la Huasteca San Luis Potosí México" en Diálogos, Revista electrónica de Historia, 11 (1): 81-110.

Allen, Patricia y Carolyn Sachs

2012 "Women and Food Chains: The Gendered Politics of Food", Taking Food Public, pp. 23-40, P. Williams Forson y Carole Counihan (eds.). Oxford y New York: Routledge.

Arzápalo, Ramón (ed.)

1995 Calepino de Motul, Diccionario Maya-Español, Tomo III. México: Universidad Nacional Autónoma de México, Instituto de Investigaciones Antropológicas.

Aulie, Wilbur H. y Evelyn Aulie

1996 Diccionario chol de Tumbalá, Chiapas, con variaciones dialectales de Tila y Sabani-

[1978] Ila, Emily F. Scharfe de Stairs (ed.). México: Instituto Linguístico de Verano. $<$ http://www.sil.org/mexico/maya/chol-tumbala/S121a-Diccionario-ctu.htm> [consultado el 18 de septiembre de 2017].

Ayora Díaz Steffan Igor

2012 Foodscapes, Foodfields and Identities in Yucatán. Amsterdam: Centro de Estudios y Documentación Latinoamericanos.

Barrera Vásquez, Alfredo (coord.)

1980 Diccionario Maya-Cordemex. Mérida: Ediciones Cordemex.

Barrera Marín, Alfredo, Alfredo Barrera Vázquez y Rosa María López Franco

1976 Nomenclatura etnobotánica maya: una interpretación taxonómica. México: Instituto Nacional de Antropología e Historia.

Barros, Cristina y Marco Buenrostro

2002 Cocina prehispánica: recetario, Arqueología Mexicana (número especial, 12).

2011 "Pozol, popo, champurrado", Revista Digital Universitaria, 12 (4). <http:// www.revista.unam.mx/vol.12/num4/art41/index.html> [consultado: 28 de mayo de 2017].

Becerra, Marcos y Heinrich Berlin

2008 Vocabulario de lengua chol (Mexico), Sebastian Matteo (recopilador y transcriptor). <http://www.wayeb.org/download/resources/berlin01.pdf> [consultado: 30 de mayo de 2017]. 
Beliaev, Dimitri, Albert Davletshin y Alexandre Tokovinine

2009 "Sweet Cacao and Sour Atole: Mixed Drinks on Classic Maya Ceramic Vases", Pre-Columbian Foodways: Interdisciplinary Approaches to Food, Culture, and Markets in Ancient Mesoamerica, pp. 257-273, John E. Staller y Michael Carrasco (eds.). New York: Springer Science y Business Media.

Beltrán de Santa Rosa, Pedro

1746 Arte de el idioma maya Reducido a Succintas Reglas, y Semilexicón Yucateco. México: por la Viuda de D. Joseph Bernardo de Hogal < https://archive.org/ details/artedeelidiomama00belt> [consultado: 30 de mayo de 2017].

Bolles, David

2001 Combined Dictionary-Concordance of the Yucatecan Mayan Language. <http://www. famsi.org/reports/96072/index.html> [consultada: 30 de mayo de 2017].

Bricker, Victoria, Eleuterio Po'ot Yah y Ofelia Dzul de Po'ot

1998 A Dictionary of the Maya Language as Spoken in Hocabá, Yucatán. Salt Lake City: University of Utah Press.

Bronson, Bennet

1966 "Roots and the Subsistence of the Ancient Maya", Southwestern Journal of Anthropology, 22: 251-279. DOI: 10.1086/soutjanth.22.3.3629373

Brown, Cecil, Eike Luedeling, Søren Wichmann y Patience Epps

2013 "The Paleobiolinguistics of Domesticated Squash (Curcubita spp.)", Explorations in Ethnobiology: The Legacy of Amadeo Rea, pp. 132-161, Quinlan, Marsha y Dana Lepofsky (eds.). Denton: Society of Ethnobiology, Department of Geography, University of North Texas.

Casas, Alejandro, José Blancas y Rafael Lira

2016 "Mexican Ethnobotany: Interactions of People and Plants in Mesoamerica", Ethnobotany of Mexico, pp. 1-20; Rafael Lira, Alejandro Casas y José Blancas (eds.). Berlin: Springer Science + Business Media.

Chevallier, Andrew

1997 Enciclopedia de las plantas medicinales. Madrid: Acento.

Chilam Balam de Chumayel

1930 Traducción del idioma maya al castellano por Antonio Mediz Bolio. San José: Ediciones del "Repertorio Americano", Imprenta y Librería Lehmann.

Cilia López, Virgina, Celia Aradillas y Fernando Díaz

2015 "Las plantas comestibles en una comunidad indígena de la Huasteca Potosina, San Luis Potosí”, Entreciencias: diálogos en la Sociedad del conocimiento, 3 (7): 143-152.

Ciudad Real, fray Antonio

1929 Diccionario de Motul. Maya español. Juan Martínez Hernández (ed.) Mérida: Talleres de la Compañía Tipográfica Yucateca S.A. 
Códice de Madrid

1888 <http://www.famsi.org/spanish/mayawriting/codices/madrid.html> [consultado el 8 de marzo 2018].

Colunga García-Marín, Patricia y Filogonio May Pat

1992 "El sistema milpero y sus recursos genéticos", La modernización de la milpa en Yucatán, Utopía o realidad, pp. 97-134, Daniel Zizumbo (ed.) Mérida: Centro de Investigación Científica de Yucatán.

Ezra, Jorge, Guillermo Acosta y Víctor Hugo García

2015 "Análisis de los granos de almidón extraídos de metates y vasijas de Xochicalco", Revista de Investigaciones Arqueométricas, 2 (2): 1-9.

Fernández Souza, Lilia y Carlos Matos Llanes

2014 "Aproximaciones multidisciplinarias a la alimentación de los mayas prehispánicos”, I Simposio de Cultura Maya Ichkantijoo, pp. 87-97. Mérida: Instituto Nacional de Antropología e Historia.

Ferrer García, José

1999 Recetario maya de Quintana Roo. México: Consejo Nacional para la Cultura y las Artes, Culturas Populares (Cocina indígena y popular, 3).

García Quintanilla, Alejandra

2000 "El dilema del Ah Kimsah K'ax, ,el que mata al monte': significados del monte entre los mayas milperos de Yucatán”, Mesoamérica, 39: 255-285.

Gracia-Arnaiz, Mabel

2010 "Alimentación y cultura en España”, Physis: Revista de Saúde Coletiva, 20 (2): 357-386.

Gran Diccionario Náhuatl

2012 México: Universidad Nacional Autónoma de México. <http://www.gdn. unam.mx > [consultado el 2 de marzo de 2018].

Guevara Chumacero, Miguel, Alejandra Pichardo y Montserrat Martínez

2017 "La tortuga en Tabasco: comida, identidad y representación", Estudios de Cultura Maya, 49: 97-122. DOI: 10.19130/iifl.ecm.2017.49.758

Harshberger, J.W.

1896 "The Purpose of Ethnobotany”, Botanical Gazette, 21 (3): 146-154.

Herrera Flores, Alejandro y Christopher Markus Götz

2014 "La alimentación de los antiguos mayas de la península de Yucatán: Consideraciones sobre la identidad y la cuisine en la época prehispánica”, Estudios de Cultura Maya, 43: 69-98. DOI: 10.1016/S0185-2574(14)70325-9 
Hjelleset, Solveig

2010 "El léxico de la comida en Guatemala. Análisis geolinguiístico", tesis de maestría en Estudios españoles y latinoamericanos. Bergen: Universidad de Bergen, Departamento de Español y Estudios Latinoamericanos.

Irigoyen Rosado, Renán

2003 Guisos y postres tradicionales de Yucatán. Mérida: Maldonado Editores del Mayab.

Isendahl, Christian

2011 "The Domestication and Early Spread of Manioc (Manihot esculenta Crantz): A Brief Synthesis”, Latin American Antiquity, 22 (4): 452-68. DOI: 10.7183/10456635.22 .4 .452

Kaufman, Terrence y John Justeson

2003 A Preliminary Mayan Etymological Dictionary. <http://www.famsi.org/reports/01051/index.html> [consultado: 15 de mayo de 2017].

Keller, Kathryn C. y Plácido Luciano

1997 Diccionario chontal de Tabasco. Tucson: Instituto Linguístico de Verano.

Landa, fray Diego de

1994 [circa 1566] Relación de las cosas de Yucatán. Estudio preliminar, cronología y revisión del texto de María del Carmen León Cázares. México: Consejo Nacional para la Cultura y las Artes (Serie Cien de México).

Lasso, Lina y Felipe Trabanino

2015 "Ts'in waj: tortillas con yuca”, Antrópica. Revista de Ciencias Sociales y Humanidades, 1 (2): 119-129.

Linares, Edelmira, Robert Bye, Daniel Rosa-Ramírez y Rogelio Pereda-Miranda

2008 "El camote", Biodiversitas, 81:11-15.

Long Solís, Janet y Luis Alberto Vargas

2005 Food Culture in Mexico. Westport/London: Greenwood Press.

Padmaja, G.

2009 "Uses an Nutritional Data of Sweetpotato", The Sweetpotato, pp. 189-233, George Thottappilly y Gad Loebenstein (eds.). Berlin: Springer Science + Business Media. DOI: 10.1007/978-1-4020-9475-0_11

Pérez, Juan Pío

1898 Coordinación alfabética de las voces del idioma maya que se hallan en el arte y obras del padre Fr. Pedro Beltrán de Santa Rosa, con las equivalencias castellanas que en las mismas se hallan, compuesta por J. Pío Pérez. Mérida: Imprenta de la Ermita. 
Pilcher, Jeffrey

1996 "Tamales or Timbales: Cuisine and the Formation of Mexican National Identity (1921-1911)", The Americas, 53 (2): 193-216. DOI: 10.2307/1007616

Pohl, Mary, Kevin O. Pope, John G. Jones, John S. Jacob, Dolores Piperno, Susan de France, David Lentz, John Gifford, Marie Danforth y Kathryn Josserand

1996 "Early Agriculture in the Maya Lowlands", Latin American Antiquity, 7 (4): 355372. DOI: $10.2307 / 972264$

Poot-Matu, José, Dora Centurión Hidalgo, Judith Espinosa Moreno, Jaime G. Cázares y Martín Mijangos

2002 "Rescate e identificación de raíces y tubérculos tropicales subexplotados del estado de Tabasco, México”, Etnobiología, 2: 59-73.

Pope, Kevin, Mary E.D. Pohl, John G. Jones, David L. Lentz, Christopher von Nagy, Francisco Vega e Irvy Quitmyer

2001 "Origin and Environmental Setting of Ancient Agriculture in the Lowlands of Mesoamerica", Science, 292 (5520): 1370-1373. DOI: 10.1126/science.292.5520.1370

Relaciones histórico-geográficas de la Gobernación de Yucatán,

1983 Mercedes de la Garza, Ana Luisa Izquierdo, María del Carmen León y Tolita Figueroa (eds.). México: Universidad Nacional Autónoma de México, Instituto de Investigaciones Filológicas, Centro de Estudios Mayas.

Sahagún, fray Bernardino de

Historia general de las cosas de la Nueva España. Libro XI: De las cosas naturales. $<$ https://www.wdl.org/es/item/10622/view/1/257/> [consultado: 18 de septiembre 2017].

Sheets, Payson, Christine C. Dixon, Adam Blanford, y Monica Guerra

2011 "Manioc Cultivation at Cerén, El Salvador: Occasional Kitchen Garden Plant or Staple Crop?", Ancient Mesoamerica, 22 (1): 1-11. DOI: 10.1017/ S0956536111000034

Signorini, Italo, Giorgio Raimondo Cardona, Carla M. Rita y Luigi Tranfo

1979 Los huaves de San Mateo del Mar, Oaxaca. México: Instituto Nacional Indigenista.

Solís Alcalá, Ermilo.

1949 Diccionario español maya. Prólogo del Lic. Antonio Médiz Bolio. Mérida: Yikal Maya Than.

Swadesh, Mauricio, María Cristina Álvarez y Juan Bastarrachea

1970 Diccionario de elementos del maya yucateco colonial. México: Universidad Nacional Autónoma de México, Coordinación de Humanidades, Centro de Estudios Mayas (Cuadernos, 3). 
Terán, Silvia, Christian Rasmussen y Olivio May Cauich

1998 Las plantas de la milpa entre los mayas. Mérida: Fundación Tun Ben Kin, A.C.

Thottappilly, George y Gad Loebenstein

2009 "Concluding Remarks", The Sweetpotato, pp. 503-513, George Thottappilly y Gad Loebenstein (eds.). Berlin: Springer Science + Business Media. DOI: 10.1007/978-1-4020-9475-0_23

Trabanino, Felipe y Lucero Meléndez

2017 "El ajkum sa' o ,pozol de camote' -una bebida entre los mayas palencanos del Clásico Tardío-", Ketzalcalli, 2016-2: 29-47.

Vassallo, Miguel

2016 "Evanescencias en las traducciones del Chilam Balam de Chumayel: el maíz y el frijol del sur, los ibes del oriente y el pozol ritual”, Estudios de Cultura Maya, 47: 119-150. DOI: 10.19130/iifl.ecm.2016.47.745

Villa Rojas, Alfonso

1978 Los elegidos de Dios: etnografía de los mayas de Quintana Roo. México: Instituto Nacional Indigenista.

Zizumbo Villareal, Daniel y Patricia Colunga García-Marín

1982 Los Huaves. La apropiación de los recursos naturales, México: Universidad Autónoma de Chapingo, Departamento de Sociología Rural.

Zizumbo Villareal, Daniel, Alondra Flores Silva y Patricia Colunga García-Marín

2012 "The Archaic Diet in Mesoamerica: Incentive for Milpa Development and Species Domestication, Economic Botany, 66 (4): 328-343. 